\title{
A Preisach method for estimating absolute paleofield intensity under the constraint of using only isothermal measurements:
}

\section{Experimental testing}

\author{
Adrian R. Muxworthy, ${ }^{1}$ David Heslop, ${ }^{2,3}$ Greig A. Paterson, ${ }^{4}$ and Daniel Michalk ${ }^{5}$ \\ Received 13 July 2010; revised 22 November 2010; accepted 19 January 2011; published 8 April 2011.
}

[1] This paper reports an empirical test of a new nonheating Preisach-based protocol for determining the absolute ancient magnetic field intensity (paleointensity) using a selection of synthetic samples and a large suite of modern lavas and pyroclastic lithic samples.

Generally, the Preisach paleointensity estimates compare favorably with the expected field intensities: (1) for the synthetic samples displaying single-domain-like behavior, the method returned the correct result for the known field, while multidomain samples yielded an underestimate, and (2) averaging 168 post-1850 A.D. lavas yielded a value $<6 \%$ within the expected field value. These Preisach paleointensity estimates are also compared with paleointensity determinations made on the same suite of samples using standard Thellier-type heating protocols and the nonheating remanence (REM) method. The Preisach paleointensity estimates compare favorably for samples that yielded correct Thellier-type determinations, including the synthetic single-domain-like samples. In addition, the Preisach method produced estimates for cases where the Thellier-type estimates failed. A possible selection criterion was identified (median destructive field), which was found to improve the paleointensity estimates in some sample suites. For the investigated sample set the Preisach method was found to be much more accurate than the REM method. The importance of cooling rate on the Preisach paleointensity estimate is also examined.

Citation: Muxworthy, A. R., D. Heslop, G. A. Paterson, and D. Michalk (2011), A Preisach method for estimating absolute paleofield intensity under the constraint of using only isothermal measurements: 2. Experimental testing, J. Geophys. Res., 116, B04103, doi:10.1029/2010JB007844.

\section{Introduction}

[2] Muxworthy and Heslop [2011] reported a new Preisachbased approach of determining absolute paleointensities (ancient magnetic field intensity) from rocks bearing a primary thermoremanence (TRM). This method differs from most other methods of determining absolute paleointensities, e.g., "Thellier-type" methods [Thellier and Thellier, 1959; Coe, 1967], in that it is nonheating. Instead of measuring a rock's response to thermoremanent acquisition in a laboratory, the Preisach-based approach predicts the hightemperature behavior from a Preisach distribution derived from room temperature measurements. The "REM-type"

\footnotetext{
${ }^{1}$ Department of Earth Science and Engineering, Imperial College London, South Kensington Campus London, UK.

${ }^{2}$ Fachbereich Geowissenschaften, Universität Bremen, Bremen, Germany.

${ }^{3}$ Now at Research School of Earth Sciences, Australian National University, Canberra ACT, Australia.

${ }^{4}$ School of Ocean and Earth Sciences, National Oceanography Centre, University of Southampton, Southampton, UK.

${ }^{5}$ Helmholz-Zentrum Potsdam, Deutsches GeoForschungsZentrum, Potsdam, Germany.

Copyright 2011 by the American Geophysical Union. 0148-0227/11/2010JB007844
}

protocol [Kletetschka et al., 2000; Gattacceca and Rochette, 2004], is currently the most commonly used nonheating method, which essentially provides a calibrated measurement of relative intensity.

[3] Muxworthy and Heslop [2011] have outlined the theoretical framework for the new protocol and in this paper we report an extensive empirical test. We consider four synthetic samples and a suite of 275 historical volcanic samples for which the geomagnetic field is accurately known at the time of eruption/emplacement.

[4] The four synthetic samples were chosen to represent "ideal" single-domain (SD) behavior (three samples) and multidomain behavior. Of the 275 natural samples, 255 are less than 100 years old, while 17 further samples were post1840 A.D. and the three samples oldest samples were from 1729 A.D. The volcanic material studied can be broadly split into two groups: (1) conventional lavas (170 samples) and (2) pyroclastic lithic deposits (105 samples). The lava samples were collected specifically for this project, while the pyroclastic lithic deposits became available through the work of Paterson and colleagues [Paterson et al., 2010b, 2010c]. Paterson and colleagues' work reports the suitability of pyroclastic lithic deposits for absolute paleointensity determination using Thellier-type protocols. As such mate- 
Table 1. Localities of the Samples and Thermomagnetic Properties

\begin{tabular}{|c|c|c|c|c|c|c|c|}
\hline $\begin{array}{l}\text { Location } \\
\text { Code }\end{array}$ & Volcano & Country & Locality & $\begin{array}{l}\text { Date of } \\
\text { Eruption } \\
\text { (A.D.) }\end{array}$ & Rock Type & $\begin{array}{c}\text { Curie } \\
\text { Temperature } \\
\left({ }^{\circ} \mathrm{C}\right)\end{array}$ & $\begin{array}{l}\text { Thermomagnetic } \\
\text { Curve Reversibility }\end{array}$ \\
\hline $\mathrm{H} 00$ & Hekla & Iceland & $63.9405 \mathrm{~N}, 019.6490 \mathrm{~W}$ & 2000 & basalt & $200-300$ & reversible \\
\hline H91 & Hekla & Iceland & $63.9599 \mathrm{~N}, 019.5952 \mathrm{~W}$ & 1991 & basalt & $300-500$ & partially \\
\hline $\mathrm{HB}$ & Hekla & Iceland & $64.0209 \mathrm{~N}, 019.7441 \mathrm{~W}$ & 1980 & basalt & $200-400$ & reversible \\
\hline $\mathrm{HG}$ & Hekla & Iceland & $63.9993 \mathrm{~N}, 019.5109 \mathrm{~W}$ & 1913 & basalt & $200-450$ & reversible \\
\hline $\mathrm{HE}$ & Hekla & Iceland & $64.0077 \mathrm{~N}, 19.5055 \mathrm{~W}$ & 1878 & basalt & $300-500$ & partially \\
\hline $\mathrm{HC}$ & Hekla & Iceland & $64.0166 \mathrm{~N}, 19.7474 \mathrm{~W}$ & 1845 & basalt & $300-500$ & partially \\
\hline KA & Krafla & Iceland & $65.4373 \mathrm{~N}, 16.5127 \mathrm{~W}$ & 1981 & basalt & $90-200$ & partially \\
\hline $\mathrm{KB}$ & Krafla & Iceland & $65.4373 \mathrm{~N}, 16.5127 \mathrm{~W}$ & 1729 & basalt & $150-250$ & reversible \\
\hline AA & Askja & Iceland & $65.0684 \mathrm{~N}, 16.7668 \mathrm{~W}$ & 1961 & basalt & $150-500$ & partially \\
\hline $\mathrm{AB}$ & Askja & Iceland & $65.0699 \mathrm{~N}, 16.7223 \mathrm{~W}$ & 1961 & basalt & $150-500$ & reversible \\
\hline $\mathrm{AC}^{\mathrm{a}}$ & Askja & Iceland & $65.0218 \mathrm{~N}, 16.6943 \mathrm{~W}$ & $1922 / 23$ & basalt & $150-300$ & partially \\
\hline $\mathrm{AD}^{\mathrm{b}}$ & Askja & Iceland & $65.0107 \mathrm{~N}, 16.7032 \mathrm{~W}$ & $1922 / 23$ & basalt & $150-250$ & reversible \\
\hline $\mathrm{AF}^{\mathrm{c}}$ & Askja & Iceland & $65.0289 \mathrm{~N}, 16.7942 \mathrm{~W}$ & 1922 & basalt & $150-450$ & reversible \\
\hline $\mathrm{AG}^{\mathrm{d}}$ & Askja & Iceland & $65.0435 \mathrm{~N}, 16.7228 \mathrm{~W}$ & 1921 & basalt & $150-300$ & partially \\
\hline $\mathrm{P} 1$ & Paricutin & Mexico & $19.3163 \mathrm{~N}, 102.1390 \mathrm{~W}$ & 1943 & basalt & $400-550$ & highly reversible \\
\hline $\mathrm{P} 2$ & Paricutin & Mexico & $19.3191 \mathrm{~N}, 102.1500 \mathrm{~W}$ & 1943 & basalt & $400-550$ & highly reversible \\
\hline VM & Vesuvius & Italy & $40.8009 \mathrm{~N}, 014.4593 \mathrm{E}$ & 1944 & basalt & $300-500$ & partially \\
\hline LV & Láscar & Chile & 23.3220S, 067.7590W & 1993 & pyroclastic lithics & $400-600$ & reversible \\
\hline M & Mount St. Helens & USA & $46.2440 \mathrm{~N}, 122.1750 \mathrm{~W}$ & 1980 & pyroclastic lithics & $500-600$ & variable \\
\hline
\end{tabular}

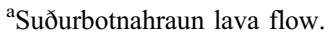

${ }^{\mathrm{b}}$ Kvíslahraun lava flow.

${ }^{\mathrm{c}}$ Mývetningahraun lava flow.

${ }^{\mathrm{d}}$ Bátshraun lava flow.

rial is not routinely used for paleointensity determination, we initially consider the lavas and the pyroclastic lithic clasts separately.

[5] In addition to comparing the paleointensity estimates determined using the Preisach approach with known geomagnetic field intensities, we compare the new method's results with values from conventional Thellier-type and REM absolute paleointensities (determined from sister samples for the Thellier-type estimates). Some of the Thellier-type determinations were conducted as part of this study and are reported here for the first time, while for other results we draw on paleointensity experiments conducted by the authors of this paper in the context of previous studies [Michalk et al., 2008; Paterson et al., 2010b]. All the REM measurements were made as part of this study.

\section{Samples}

\subsection{Synthetic Samples}

[6] We considered three ideal single-domain (SD) samples synthesized by Ferk et al. [2010] by the remelting of natural phonolitic glass from Lavas Negras obtained from the north side of Teide, Tenerife. Heating and cooling thermomagnetic curves measured by Ferk et al. [2010] indicated an absence of alteration. Determinations of second derivatives for the thermomagnetic curves of all samples indicate a Curie temperature $\left(T_{\mathrm{C}}\right)$ between $410^{\circ} \mathrm{C}$ and $460^{\circ} \mathrm{C}$, corresponding to titanomagnetite $\left(\mathrm{Fe}_{3-\mathrm{x}} \mathrm{Ti}_{\mathrm{x}} \mathrm{O}_{4}\right)$ with a titanium content of $\mathrm{x} \approx 0.22$. Ferk et al. [2010] observed a small kink between 70 and $90^{\circ} \mathrm{C}$, which they attribute to the presence of hemoilmenite $\left(\approx \mathrm{Fe}_{1.4} \mathrm{Ti}_{0.6} \mathrm{O}_{3}\right)$. This hemoilmenite fraction, however, has a negligible contribution to the overall magnetization.

[7] For comparison, we also analyzed a previously studied synthetic multidomain magnetite sample W (11 $\mu \mathrm{m})$ [Muxworthy and Dunlop, 2002; Muxworthy et al., 2005].
This powdered sample was obtained from Wright Industries Inc., and has a mean size of $11 \pm 3 \mu \mathrm{m}$. Mössbauer spectra were measured; assuming a cation deficient model, i.e.,

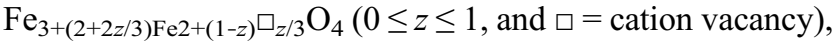
$\mathrm{W}(11 \mu \mathrm{m}) z$ has a value of 0.009 [Muxworthy et al., 2003].

\subsection{Basaltic Lavas}

[8] We have collected historical basaltic lavas from Iceland, Mexico and Italy (Table 1). The Icelandic lavas are associated with eruptions from three volcanoes; a series of dated lava flows (1845, 1878, 1913, 1980, 1991 and 2000 A.D.) from Mount Hekla in southwest Iceland, two lava flows (1729 and 1981 A.D.) from Mount Krafla in the northeast of Iceland, and five 20th century flows from Mount Askja in the central highlands (the Bátshraun lava flow (1921), the Mývetningahraun lava flow (1922), the Suðurbotnahraun lava flow (1922 or 1923), the Kvíslahraun lava flow (1922 or 1923) and the 1961 lava flow [Hjartardóttir et al., 2009]). The Krafla samples were taken from the two most recent basaltic fissure eruptions in the Krafla volcanic system. This system is dominated by the eruption of tholeiitic basalts, which form by adiabatic decompression melting of unusually hot mantle under a spreading center. In contrast, the transitional basalts that are parental to the Hekla system are generated by mantle melting under a southward propagating rift segment. Mount Askja is a stratovolcano situated in the center of Iceland in the $200 \mathrm{~km}$ long Askja fissure swarm, and last erupted in 1961 A.D. Mount Askja is now dominated by a large caldera lake, which is the result of a Plinian eruption in 1875 A.D. Ore microscopy revealed that the Icelandic samples from Hekla generally consisted of homogeneous unoxidized euhedral titanomagnetite grains between 5 and $20 \mu \mathrm{m}$ in size (C1 oxidation state [Haggerty, 1991]), with large amounts of fine submicron titanomagnetite $(\mathrm{C} 1)$ and ilmenite (R1) needles. The presence of needles is indicative of fast cooling. The samples from Krafla consisted of 
small skeletal titanomagnetites (C1) similar to those reported by Krása and Matzka [2007].

[9] For this study, we sampled two sections of the 1943 A.D. lava flow of Paricutin, Mexico (active period, 1943-1952), which is located within the Trans-Mexican Volcanic Belt. One sampling locality (P1, Table 1) was a direct resampling of a site previously reported by Dekkers and Böhnel [2006]. Ore microscopy revealed that most samples consisted of homogeneous unoxidized euhedral titanomagnetites grains (C1), though some samples displayed evidence for additional low-temperature oxidation through shrinkage cracks [Petersen and Vali, 1987].

[10] Vesuvius (properly Somma-Vesuvius) in the Bay of Naples, Italy, has an unparalleled record of historical activity. From the last large Plinian eruption in 1631 A.D. to 1944 A.D., Vesuvius was virtually continually in some form of eruptive state [Kilburn and McGuire, 2001]. We have sampled the most recent lava flows from the large 1944 A.D. eruption.

\subsection{Pyroclastic Lithic Clasts}

[11] Paterson et al. [2010b] sampled lithic clasts from pyroclastic deposits from four volcanoes. Of these, three were found to be emplaced "hot"; that is, the pyroclastic lithic clasts from a single deposit all recorded the same wellconstrained paleomagnetic direction. A "cold" emplacement could be due to reworking as part of lahars. Of these three deposits, two were from modern eruptions: the 1980 A.D. eruption of Mount St. Helens and the 1993 A.D. eruption of Volcán de Láscar, Chile (Table 1).

[12] Mount St. Helens is located in the Cascade Mountain Range of the western United States and is famous for its devastating Plinian eruption on 18 May 1980. Within days to weeks of the pyroclastic deposits being emplaced, direct temperature measurements were taken by a group from the United States Geological Survey [Banks and Hoblitt, 1981]. Some of the pyroclastic deposits were estimated to be emplaced between $300^{\circ} \mathrm{C}$ and $>600^{\circ} \mathrm{C}$.

[13] A total of 113 clasts were collected from 6 different sites on the northern flank of Mount St. Helens [Paterson et al., 2010b]. The lithic clasts include basalts, andesites and dacites. Thermal demagnetization revealed clasts with both single and multiple components of magnetic remanence. From this sample set the 61 clasts with only one remanence component, i.e., emplacement occurred above their Curie temperature, and one clast with two remanence components were used for Thellier-type paleointensity analysis [Paterson et al., 2010b].

[14] Volcán de Láscar is a stratovolcano in the Chilean Andes, near the Argentinean border. On 18 April 1993, Láscar erupted for 3 days in what was the largest historical eruption in the northern Andes. Two intense eruptions on 19 April produced ejecta columns as high as $22 \mathrm{~km}$. Pyroclastic density currents resulted on 19 and 20 April following the collapse of eruptive columns. The pyroclastic deposits contain a pumice-rich facies comprising of an andesiticdacitic juvenile component with a minor lithic content [Sparks et al., 1997]. The lithic-rich facies incorporates roughly equal proportions of eroded and vent-derived lithic clasts. These include fragments of the preexisting andesitic lava dome, formed in 1992, and clasts from the TumbresTalabre lava.
[15] A total of 111 clasts, representing 31 sites from pyroclastic deposits on both flanks of Láscar, were collected [Paterson et al., 2010c]. All the samples were found to be emplaced above their Curie temperature, although some were found to be self-reversing. A suite of 46 clasts were considered for Thellier-type paleointensity analysis [Paterson et al., 2010b].

\section{Experimental Methods}

[16] Drill cores with a diameter of $10 \mathrm{~mm}$ (minicores) were collected and orientated for the lavas from Iceland, Mexico and Italy. In the laboratory, samples were cut into specimens of 9-10 mm length, which yielded 2-5 specimens for each drill core. The pyroclastic lithic deposits were collected as oriented handheld specimens, and cores with a diameter of 10 or $20 \mathrm{~mm}$ were later drilled from these clasts [Paterson et al., 2010b, 2010c].

[17] As described by Muxworthy and Heslop [2011], to make a Preisach based paleointensity estimation, the sample's natural remanent magnetization (NRM) must be first measured and then alternating field (AF) demagnetized to identify any secondary magnetization components. Subsequently, a first-order reversal curve (FORC) diagram is measured. For normalization purposes, the saturation isothermal remanence (SIRM) is also measured. For the synthetic samples, just the primary thermoremanence (TRM) was considered; that is, the samples' magnetizations were not AF demagnetized.

[18] In addition to the Preisach paleointensity analysis, we also conducted Thellier-type paleointensity measurements on sister samples, as well as other routine rock magnetic analysis. In this study samples were measured at five different laboratories (Imperial College London; Helmholtz Centrum Potsdam, Germany; the Institute for Rock Magnetism (IRM), University of Minnesota, United States; and the universities of Southampton and Oxford, United Kingdom) using a range of instruments.

[19] AF demagnetization experiments were made using automated 2G SQUID magnetometers at the Helmholtz Centrum Potsdam, the IRM, and the University of Southampton. The SIRM normalization parameter was measured using the same instrument as the AF demagnetization curves to remove any inconsistencies due to incorrect calibration. For the Preisach paleointensity method the ratio NRM/ SIRM is required.

[20] The FORC measurements were made using the Princeton Measurements Corporation Alternating Gradient Magnetometer (AGM) at the Helmholtz Centrum Potsdam and Princeton Measurements Corporation Vibrating Sample Magnetometers (VSM) at the University of Southampton and the IRM On the VSM, the $10 \mathrm{~mm}$ cores used to determine the NRM could be measured directly. For the AGM measurement, smaller chips had to be subsampled from the $10 \mathrm{~mm}$ cores. The SIRM of these chips and the $10 \mathrm{~mm}$ cores was measured, to allow for normalization of the differing sample sizes. In addition to measuring the FORC curves, standard hysteresis curves and back-field curves were measured for each sample to provide a routine rock magnetic quantification [Day et al., 1977].

[21] The Thellier-type measurements for the Icelandic samples were conducted using an Agico JR6A spinner 

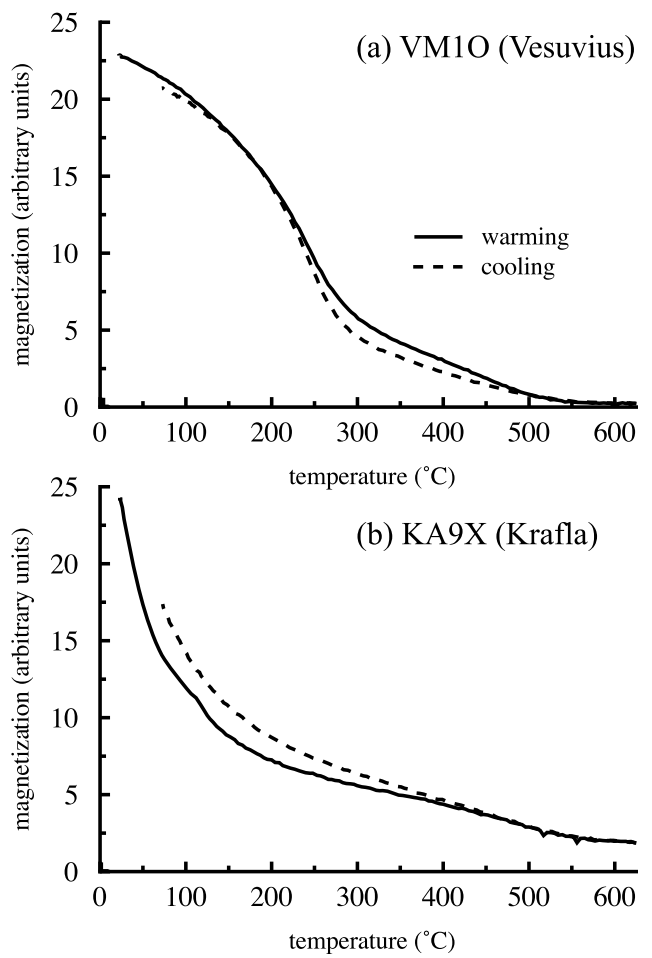

Figure 1. Representative thermomagnetic curves for (a) sample VM1O from Vesuvius and (b) sample KA9X from Krafla. A field of $500 \mathrm{mT}$ was applied during the measurement.

magnetometer and a temperature and field-calibrated MMTD oven at the Helmholtz Centrum [Michalk et al., 2008]. Thellier-type estimates for the synthetic samples and the lavas from Paricutin and Vesuvius, were made using a fully automated low-field $(<100 \mathrm{nT})$, high-temperature three-axis Orion VSM located at Imperial College London. The pyroclastic samples' Thellier-type paleointensity measurements were made at the University of Southampton, using an ASC Scientific single-chamber oven [Paterson et al., 2010b]. The pyroclastic remanences were measured using a $2 \mathrm{G}$ Enterprises SQUID magnetometer, an Agico JR5A spinner magnetometer or a Molspin Minispin magnetometer. During the Thellier-type paleointensity measurements of the Icelandic lavas and pyroclastic samples, low-field susceptibility $(\chi)$ was measured on a Bartington Instruments MS2B magnetic susceptibility meter to monitor thermally induced chemical alteration. The majority of the Thellier-type paleointensity estimations were made using the double-heating protocol [Coe, 1967] with partial TRM (pTRM) checks and pTRM tails checks, with only the lavas from Iceland and the pyroclastic deposits from Mount St. Helens being analyzed using the IZZI paleointensity protocol [Yu et al., 2004].

[22] The REM paleointensity estimates are obtained from the NRM/SIRM ratio required for the Preisach paleointensity method, i.e., REM paleointensity $=3000 \times \mathrm{NRM} / \mathrm{SIRM} \mu \mathrm{T}$. While more complicated variants of the REM method are often applied [e.g., Acton et al., 2007] as our samples are recently magnetized basalts and pyroclastic lithic clasts, very few samples displayed secondary magnetizations, and thus standard REM determinations can be applied.
[23] To estimate the thermal stability and Curie temperatures of the lava samples, high-temperature saturation curves were measured with a Petersen Instruments Variable Field Translation Balance (VFTB) from room temperature to $700^{\circ} \mathrm{C}$ using a field of $500 \mathrm{mT}$ on one to five samples per flow. For the pyroclastic lithics, thermomagnetic or susceptibility-temperature curves were measured using the VSM (applied field 1T) at the University of Southampton, or using an Agico KLY-2 Kappabridge magnetic susceptibility meter with furnace attachment at the University of Oxford.

\section{Results}

\subsection{Rock Magnetic Analysis}

4.1.1. Thermomagnetic Analysis

[24] The basaltic lava samples from Vesuvius generally display two Curie temperature ranges (Figure 1a), one near $250-350^{\circ} \mathrm{C}$ that is indicative of high-Ti titanomagnetite and a second between 450 and $550^{\circ} \mathrm{C}$, which is indicative of low-Ti titanomagnetite (Table 1). The thermomagnetic curves are partially reversible when heating/cooling up to $650^{\circ} \mathrm{C}$.

[25] All the Hekla samples with the exception of the 1913 A.D. flow, display a wide range of Curie temperatures, generally with a dominant phase between $200^{\circ} \mathrm{C}$ and $350^{\circ} \mathrm{C}$, and a second phase with higher Curie temperatures between $510^{\circ} \mathrm{C}$ and $560^{\circ} \mathrm{C}$. Both Curie temperatures are seen in the heating and cooling curves, and the samples are mostly or at least partially reversible. The 1913 A.D. flow displays a single wide Curie temperature range that is reversible on cooling (Table 1).

[26] The samples from Krafla and Askja display low Curie temperatures (Table 1). The 1981 A.D. flow from Krafla (Figure 1b) is only partially reversible on cooling. These findings for the Icelandic samples agree with the previous analysis of Michalk et al. [2008].

[27] The samples from Paricutin display a single ferromagnetic phase with a broad Curie temperature $\left(T_{C}\right)$ between 400 and $550^{\circ} \mathrm{C}$ (Table 1), which is likely to be due to titanomagnetite that has undergone some degree of hightemperature (deuteric) oxidation. Heating and cooling branches show excellent reversibility, indicating that no thermal alteration occurs. Similar findings have been reported by Michalk et al. [2008].

[28] Thermomagnetic curves for the pyroclastic samples have been described in detail by Paterson et al. [2010b, 2010c]. Their findings are summarized in Table 1. Generally, all the pyroclastic lithic samples display high Curie temperatures. The samples from Volcán de Láscar, Chile, are often reversible on cooling, while only some of the samples from Mount St. Helens were reversible (Table 1).

[29] As mentioned above, the thermomagnetic behavior of the three synthetic glass samples were analyzed by Ferk et al. [2010]. The samples were chemically stable to heating, with Curie temperatures between $410^{\circ} \mathrm{C}$ and $460^{\circ} \mathrm{C}$. The synthetic multidomain magnetite sample $\mathrm{W}(11 \mu \mathrm{m})$ had a Curie temperature of $577^{\circ} \mathrm{C}$ and was chemically stable on heating.

\subsubsection{Magnetic Hysteresis}

[30] The ratios of the magnetic hysteresis parameters, i.e., the coercive force $H_{C}$, the remanent coercive force $H_{C R}$, the saturation magnetization $M_{S}$ and the remanent saturation magnetization $M_{R S}$ (or SIRM) are shown for all the samples on a "Day plot" [Day et al., 1977] in Figure 2. 


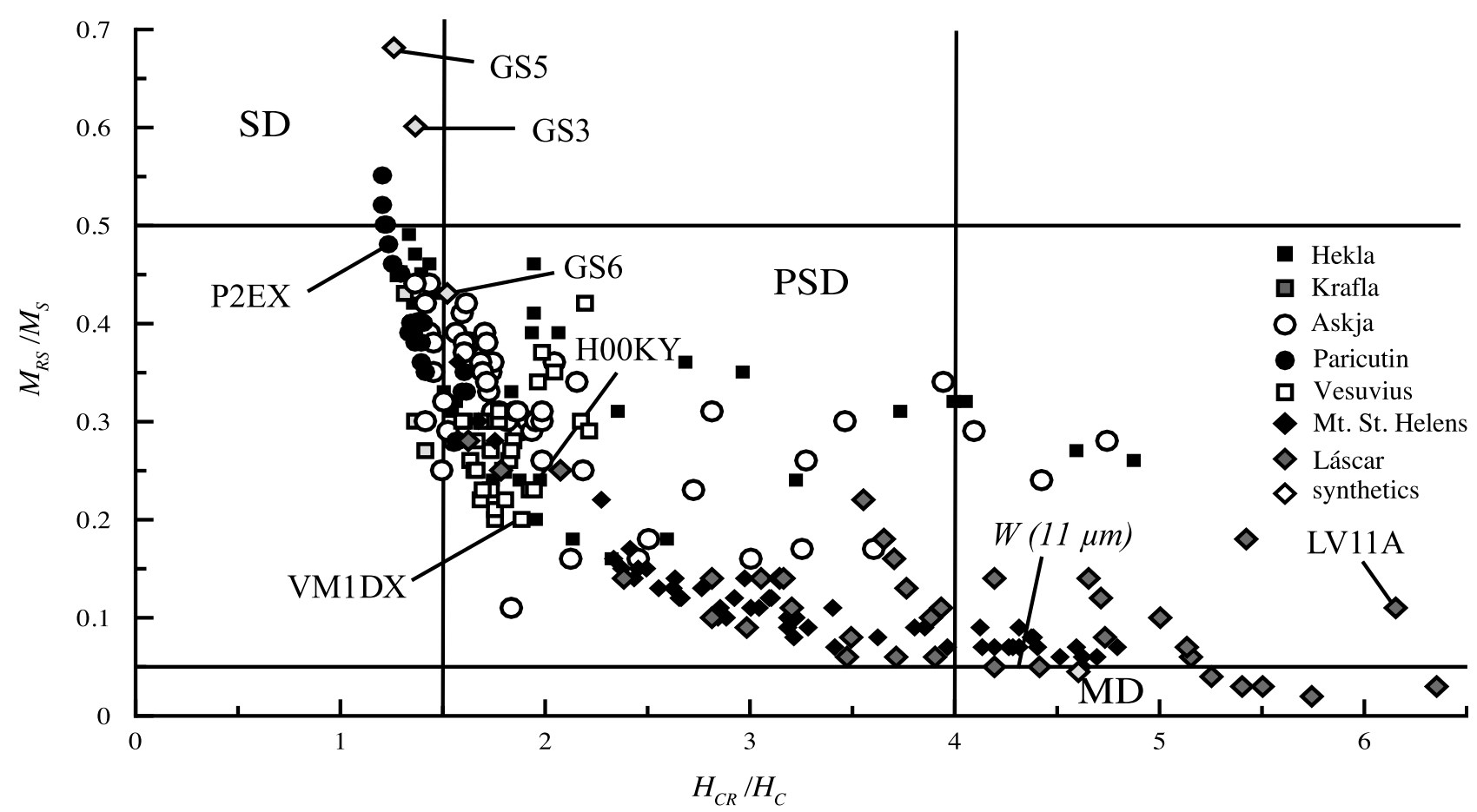

Figure 2. A Day plot [Day et al., 1977] of the ratios of the hysteresis parameters $M_{R S} / M_{S}$ versus $H_{C R} / H_{C}$ for seven suites of samples in this study plus the synthetic glass samples and $\mathrm{W}(11 \mu \mathrm{m})$. The regions commonly associated with SD, PSD, and MD behavior are labeled. Samples P2EX, H00KY, LV11A and VM1DX discussed in the text are highlighted. Their FORC distributions are depicted in Figure 3.

[31] The three synthetic glass samples (GS3, GS5 and GS6) plotted toward or in the SD box represented on the Day plot (Figure 2); GS3 and GS5 had $M_{R S} / M_{S}$ ratios above 0.5 , suggesting they are $\mathrm{SD}$ and controlled by an anisotropy with a higher order than uniaxial. Saturation appeared to be reached [Fabian, 2006]. The $M_{R S} / M_{S}$ for ideal SD magnetite with cubic anisotropy is 0.866 [Kneller, 1969]. Sample GS6 displayed more pseudo-SD (PSD)-like behavior. The synthetic multidomain (MD) sample's (W $(11 \mu \mathrm{m})$ ) hysteresis properties position it within the MD box on the Day plot (Figure 2).

[32] Generally, the basaltic lava samples, notably those from Krafla and Paricutin, plot toward the SD region, and the pyroclastic lithic samples toward the MD zone. The lavas from Askja and Vesuvius plot in the middle of the PSD region. The high $M_{R S} / M_{S}$ ratios for the Paricutin and Krafla samples may be due to the observed low-temperature oxidation [Wang et al., 2006]. Some of the samples, mostly from Volcán de Láscar, Hekla and Askja, plot in the area above the MD region on the right-hand side of the PSD region, this behavior is often attributed to thermal relaxation, i.e., superparamagnetism [Jackson et al., 1990]. The Hekla samples that plot within this area all come from the 1845 A.D. eruption and from the Suðurbotnahraun (AC) and Mývetningahraun (AF) lava flows for the Askja data (see Data Set S1 in the auxiliary material). ${ }^{1}$

[33] For the purposes of rock magnetic characterization, we also display example FORC diagrams of the samples (Figure 3). Generally, samples displaying SD, PSD, and MD

\footnotetext{
${ }^{1}$ Auxiliary materials are available at $\mathrm{ftp} / / / \mathrm{ftp}$.agu.org/apend/jb/
} $2010 J B 007844$. characteristics, as indicated by their position on the Day plot (Figure 2), display corresponding FORC diagrams [e.g., Roberts et al., 2000; Muxworthy and Roberts, 2007]. For example, the sample P2EX from Paricutin, displays an SD-like FORC diagram (Figures 3a), and plots near the SD region on Figure 2. Samples from Láscar, e.g., LV11A (Figure 3b), which fall outside the usual regions on Figure 2, contain two distinct peaks in their FORC diagrams; one peak is associated with a low-coercivity magnetization, and a second with much higher coercive force magnetization likely to be a highly stable magnetic remanence carrier. Examination of the Day plot alone (Figure 2) belies the potential of such samples. Most samples displayed typical PSD behavior, e.g., like H00KY from Hekla and VM1DX from Vesuvius (Figures 2 and 3). The samples that plot in the area above the MD region on the right-hand side of the PSD region (Figure 2), typically display twin-peaked FORC diagrams similar to LV11A (Figure 3b).

[34] The synthetic glass samples displayed FORC diagrams representative for noninteracting SD grains (Figure 4). Samples GS3 and GS6 have clear bimodal coercivity distributions (Figure 4). The anisotropy does not appear to be dominated by uniaxial behavior, as the expected negative region in the lower half of the FORC diagram toward the origin is not clearly defined [Muxworthy et al., 2004; Newell, 2005]; however, the FORC distributions for GS3 and GS5 do display a slight reduction in the FORC distribution in this region. Unfortunately, the samples were relatively magnetically weak $\left(M_{S} \approx 5-20 \times 10^{-7} \mathrm{~A} \mathrm{~m}^{2}\right)$, giving rise to substantial noise in the FORC diagram (Figure 4). W $(11 \mu \mathrm{m})$ displays a FORC diagram attributed to PSD/MD behavior (Figure 5). 
(a) P2EX (Paricutin)

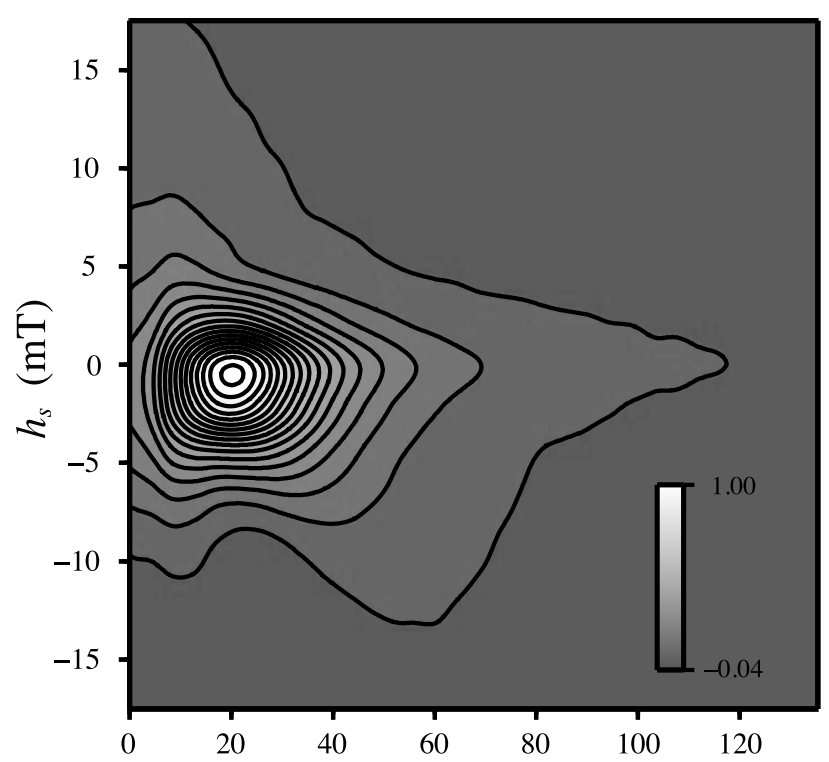

(c) H00KY (Hekla, 2000)

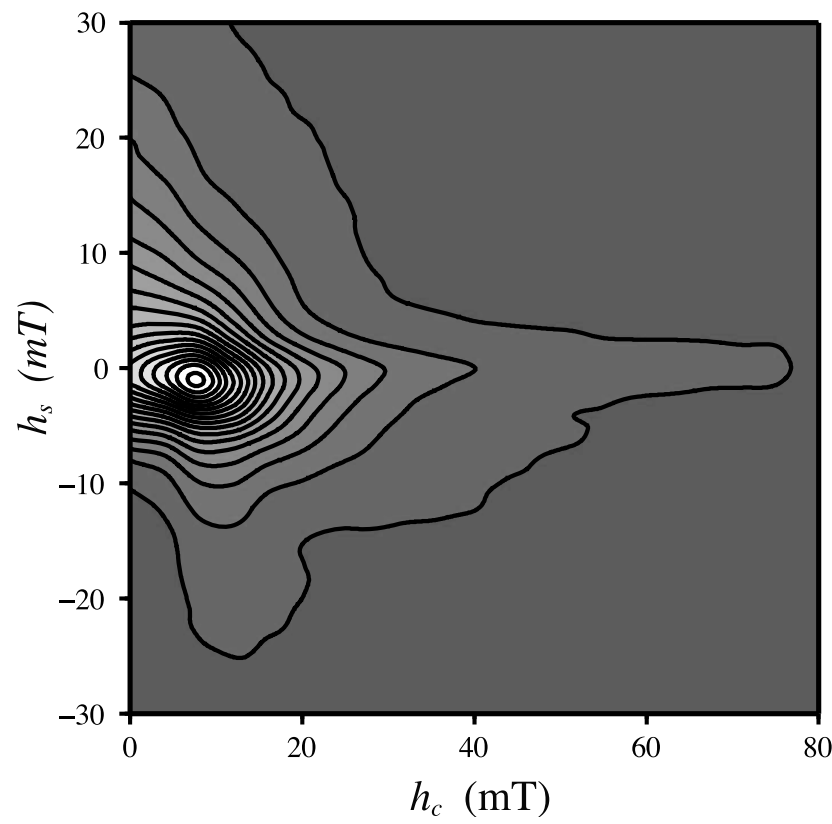

(b) LV11A (Láscar)

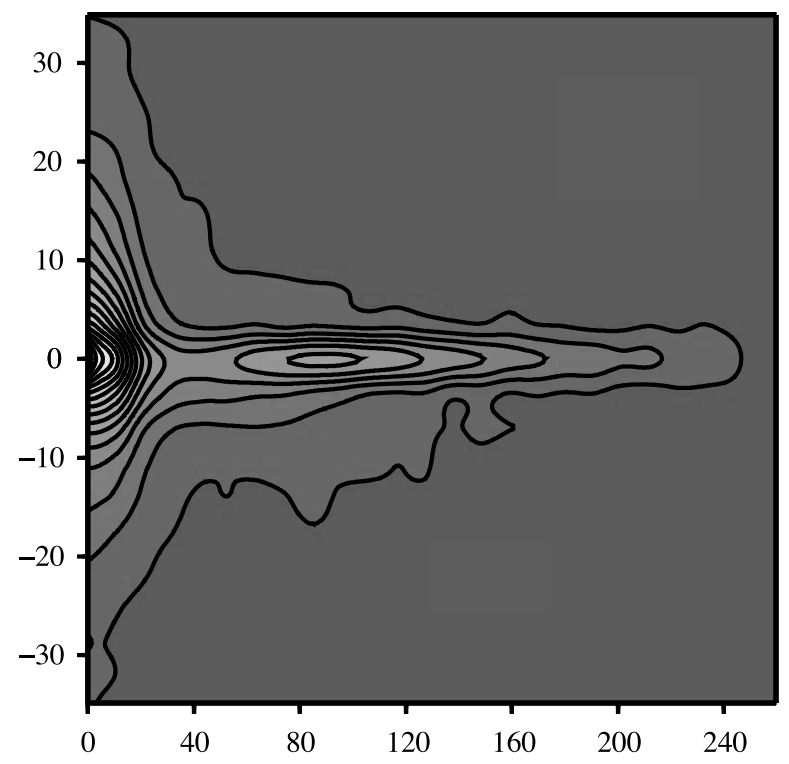

(d) VM1DX (Vesuvius)

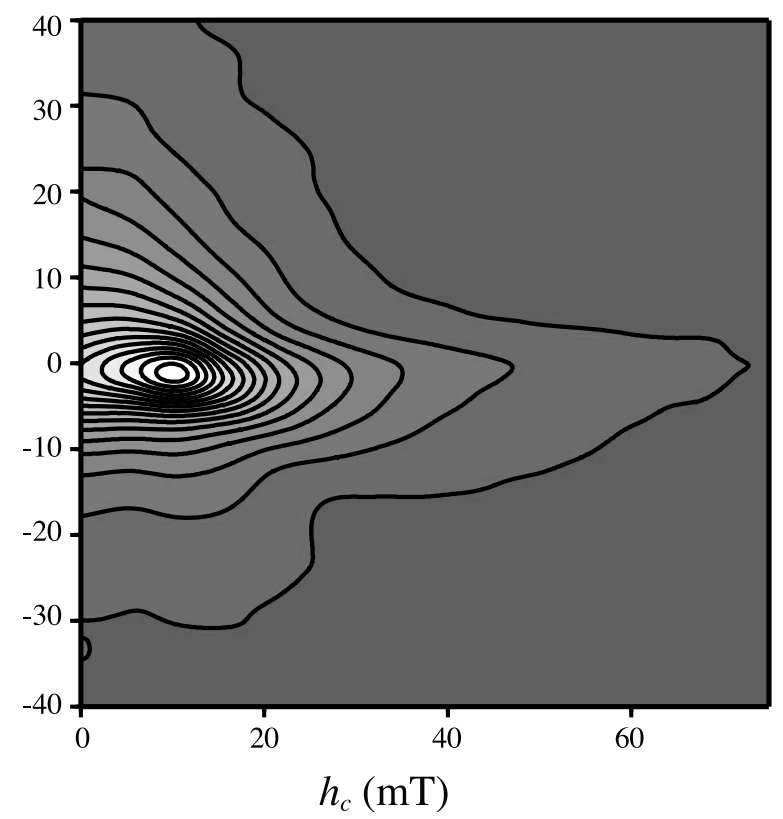

Figure 3. Normalized FORC diagrams for samples (a) P2EX (Paricutin, Mexico), (b) LV11A (Láscar, Chile), and (c) H00KY (2000 A.D. eruption of Hekla, Iceland), and (d) VM1DX (Vesuvius, Italy). The smoothing factor (SF) in all four diagrams is 2. The averaging time during the measurement was $100 \mathrm{~ms}$. Note the different scales for each diagram.

\subsection{Preisach Paleointensity Estimations}

[35] To make a paleointensity estimate on natural samples using the Preisach protocol as outlined by Muxworthy and Heslop [2011], it is necessary to initially measure the natural remanent magnetization (NRM) of a sample and its alternating field (AF) demagnetization curve. The $\mathrm{AF}$ demagnetization data are then plotted on an orthogonal projection plot [Zijderveld, 1967], and the primary remanent magnetization identified as well as the alternating field required to demagnetize secondary components. Samples where a primary magnetization was difficult to identify due to noise or curvature were rejected. As discussed by Muxworthy and Heslop [2011], a paleointensity estimate is made for each point on the AF demagnetization curve that is beyond the peak field required to remove secondary magnetizations.

[36] In section 4.1.2 the measurement of FORC diagrams was discussed and interpreted in terms of what information they yield concerning domain state and magnetostatic interactions; however, the prime reason for their measurement 
(a) GS3

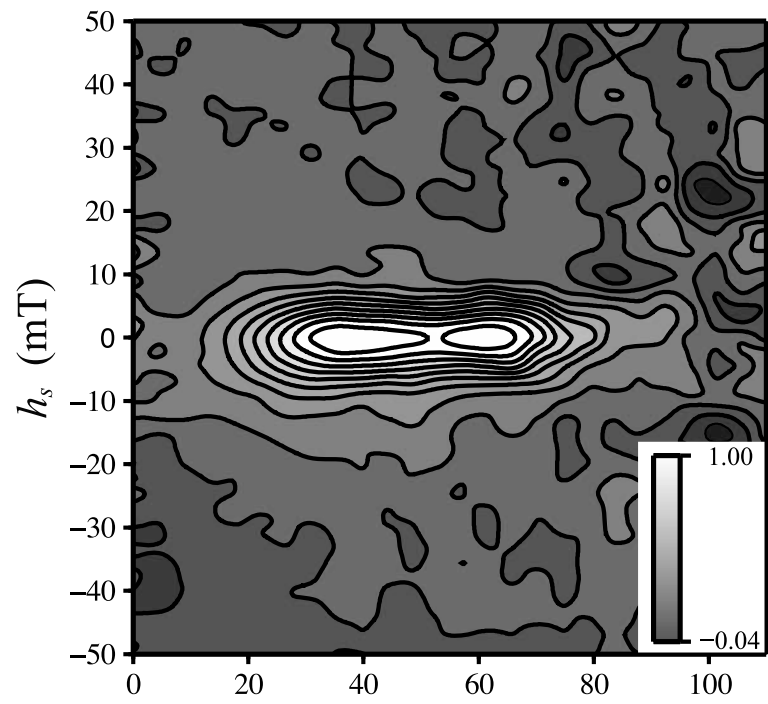

(b) GS5

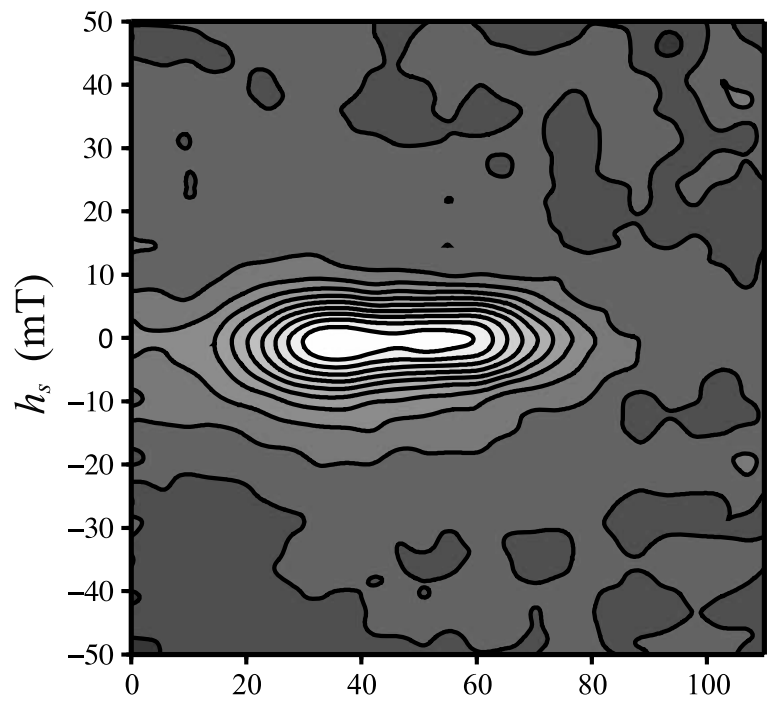

(c) GS6

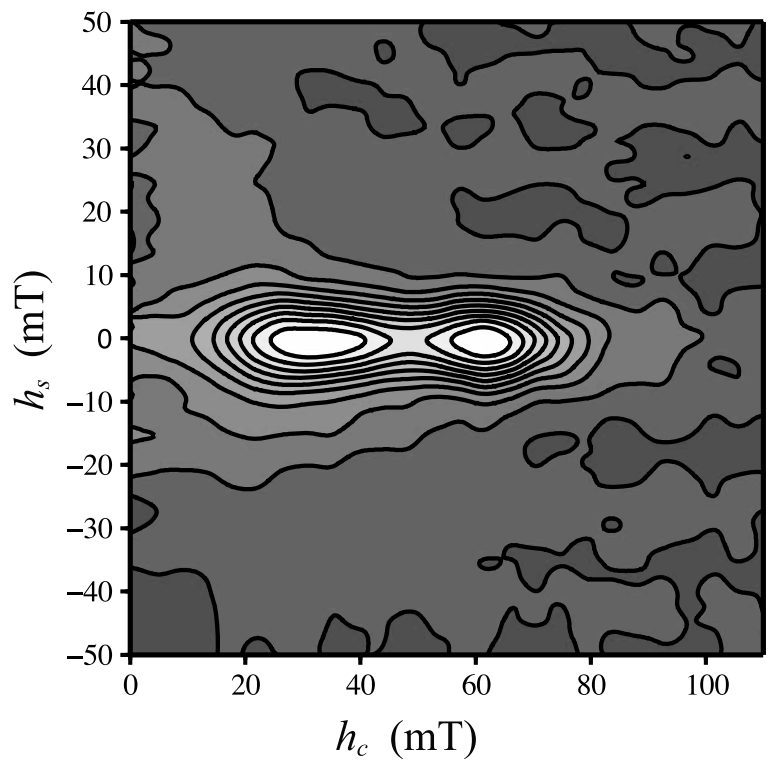

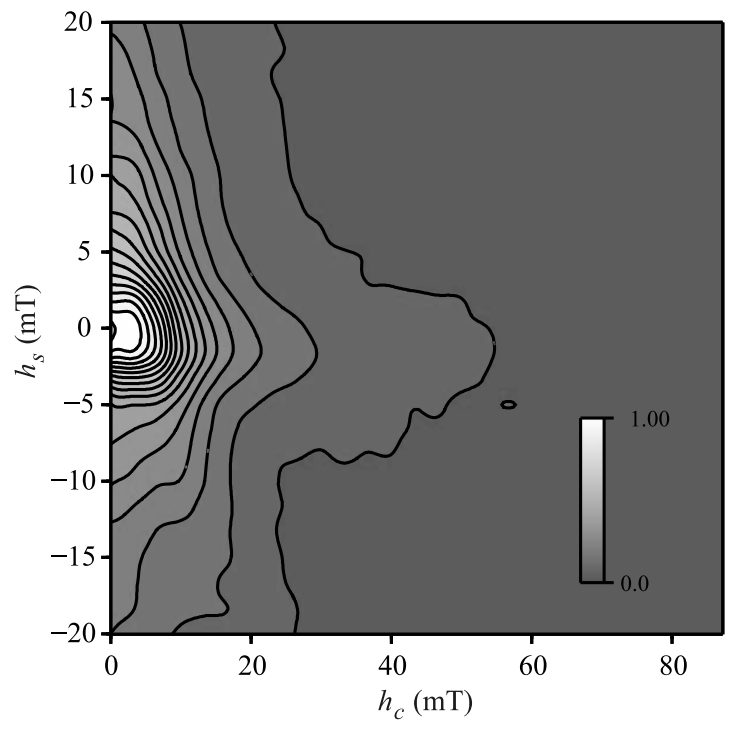

Figure 5. A FORC diagram for the synthetic sample $\mathrm{W}$ $(11 \mu \mathrm{m})(\mathrm{SF}=2$, averaging time was $100 \mathrm{~ms})$.

was to build the input Preisach distributions to be used in the Preisach paleointensity protocol. Nearly all the lava samples in this study produced "high-quality" FORC diagrams with high signal-to-noise ratios; thus, few samples were rejected based upon the quality of their FORC diagrams; the samples with the poorest quality signals were, in fact, the three synthetic glass samples (Figure 4).

[37] Using the $\mathrm{AF}$ demagnetization data, the measured SIRM and the FORC data, the paleointensity estimates were made for each sample using the numerical protocol described in detail by Muxworthy and Heslop [2011]. Using $2 \times 10^{6}$ hysterons, the protocol takes approximately $1-2 \mathrm{~min}$ to make a paleointensity estimate on a standard personal computer. For the natural samples, a total cooling time of 1 month was employed for all the paleointensity estimates. For the synthetic samples the known laboratory cooling time was used.

[38] The protocol produces a paleointensity estimate for each sample, with an associated standard deviation. In Table 2, the average paleointensity estimates are shown for each flow unit. Means, standard deviations and 95\% confidence intervals $\left(\mathrm{CI}_{95}\right)$ are tabulated [Paterson et al., 2010a]. The standard deviation gives an estimate of the width of the distribution, whereas the $\mathrm{CI}_{95}$ describes a range within which the mean is likely to be [Borradaile, 2003]. The width of the $\mathrm{CI}_{95}$ is inversely proportion to the square root of the number of samples.

[39] In sections 4.2.1-4.2.3 we report Preisach-based paleointensity determinations for the described samples. As basaltic lavas are employed more commonly than pyroclastic lithics in paleointensity studies, we will treat the results for these two types of samples separately.

Figure 4. Normalized FORC diagrams for the three glass samples: (a) GS3, (b) GS5, and (c) GS6. The samples were particularly weak; a smoothing factor of 5 was used to produce these images (averaging time was $150 \mathrm{~ms}$ ). 
Table 2. Paleointensity Estimates for the Basaltic Lavas and Pyroclastic Deposits

\begin{tabular}{|c|c|c|c|c|c|c|c|c|c|c|c|}
\hline \multirow[b]{3}{*}{ Volcano } & \multirow{3}{*}{$\begin{array}{c}\text { Date of } \\
\text { Eruption } \\
\text { (A.D.) }\end{array}$} & \multirow[b]{3}{*}{$\begin{array}{l}\text { Location } \\
\text { Code }\end{array}$} & \multirow[b]{3}{*}{$\begin{array}{l}\text { Geomagnetic } \\
\text { Field }^{\mathrm{a}}(\mu \mathrm{T})\end{array}$} & \multicolumn{8}{|c|}{ Paleointensity Estimates (With Standard Deviation) } \\
\hline & & & & \multicolumn{3}{|c|}{ Preisach } & \multicolumn{3}{|c|}{ Thellier-Type } & \multicolumn{2}{|c|}{ REM } \\
\hline & & & & $\begin{array}{l}\text { Success } \\
\text { Ratio }^{\text {b }}\end{array}$ & $\begin{array}{l}\text { Mean } \\
(\mu \mathrm{T})\end{array}$ & $\begin{array}{l}\mathrm{CI}_{95} \\
(\mu \mathrm{T})\end{array}$ & $\begin{array}{l}\text { Success } \\
\text { Ratio }^{\mathrm{b}}\end{array}$ & $\begin{array}{l}\text { Mean } \\
(\mu \mathrm{T})\end{array}$ & $\begin{array}{l}\mathrm{CI}_{95} \\
(\mu \mathrm{T})\end{array}$ & $\begin{array}{c}\text { Mean } \\
(\mu \mathrm{T})\end{array}$ & $\begin{array}{l}\mathrm{CI}_{95} \\
(\mu \mathrm{T})\end{array}$ \\
\hline \multicolumn{12}{|c|}{ Basaltic Lavas } \\
\hline \multirow{6}{*}{ Hekla } & 2000 & $\mathrm{H} 00$ & 52 & $5 / 5$ & $48 \pm 17$ & $28-68$ & $3 / 4$ & $62 \pm 2$ & $59-65$ & $71 \pm 32$ & $34-108$ \\
\hline & 1991 & H91 & 52 & $5 / 5$ & $34 \pm 10$ & $23-45$ & & & & $52 \pm 13$ & $37-67$ \\
\hline & 1980 & HB & 52 & $4 / 4$ & $42 \pm 15$ & $22-62$ & $1 / 5$ & $60 \pm 4$ & $50-70$ & $70 \pm 17$ & $48-92$ \\
\hline & 1913 & HG & 52 & $4 / 4$ & $44 \pm 4$ & $40-48$ & $4 / 5$ & $43 \pm 7$ & $35-51$ & $60 \pm 5$ & $54-66$ \\
\hline & 1878 & $\mathrm{HE}$ and $\mathrm{HG}$ & 52 & $11 / 11$ & $65 \pm 20$ & $52-78$ & $2 / 5$ & $46 \pm 5$ & $40-52$ & $85 \pm 12$ & $77-93$ \\
\hline & 1845 & $\mathrm{HC}$ & 52 & $6 / 6$ & $152 \pm 25$ & $127-177$ & & 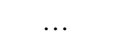 & & $189 \pm 20$ & $171-207$ \\
\hline Average $^{c}$ & & & 52 & $29 / 35$ & $51 \pm 21$ & $44-58$ & $10 / 19$ & $50 \pm 10$ & $43-57$ & $71 \pm 20$ & $62-80$ \\
\hline \multirow[t]{2}{*}{ Krafla } & 1981 & KA & 52 & $3 / 3$ & $50 \pm 3$ & $43-57$ & & $\ldots$ & $\ldots$ & $165 \pm 2$ & $162-168$ \\
\hline & 1729 & $\mathrm{~KB}$ & 52 & $3 / 3$ & $34 \pm 3$ & $30-38$ & $0 / 4$ & $\ldots$ & $\ldots$ & $83 \pm 11$ & $67-99$ \\
\hline \multirow[t]{5}{*}{ Askja } & 1961 & $\mathrm{AA}$ and $\mathrm{AB}$ & 49.5 & $20 / 22$ & $52 \pm 20$ & $33-71$ & $\ldots$ & $\ldots$ & $\ldots$ & $86 \pm 61$ & $57-115$ \\
\hline & $1922 / 23$ & $\mathrm{AC}$ & 49.5 & $12 / 14$ & $50 \pm 22$ & $37-63$ & $\ldots$ & $\ldots$ & $\ldots$ & $67 \pm 35$ & $46-88$ \\
\hline & $1922 / 23$ & $\mathrm{AD}$ & 49.5 & $19 / 24$ & $44 \pm 9$ & $39-4$ & $\ldots$ & $\ldots$ & $\ldots$ & $52 \pm 9$ & $48-56$ \\
\hline & 1922 & $\mathrm{AF}$ & 49.5 & $6 / 6$ & $82 \pm 59$ & $20-142$ & $\ldots$ & $\ldots$ & $\ldots$ & $94 \pm 60$ & $39-149$ \\
\hline & 1921 & $\mathrm{AG}$ & 49.5 & $6 / 6$ & $43 \pm 8$ & $35-52$ & $\ldots$ & $\ldots$ & $\ldots$ & $73 \pm 12$ & $61-85$ \\
\hline Average & & & 49.5 & $62 / 72$ & $51 \pm 32$ & $43-59$ & $\ldots$ & $\ldots$ & $\ldots$ & $72 \pm 45$ & $60-84$ \\
\hline Paricutin & 1943 & $\mathrm{P} 1$ and P2 & 45 & $23 / 25$ & $80 \pm 28$ & $65-95$ & $29 / 41$ & $49 \pm 12$ & $44-54$ & $165 \pm 60$ & $139-191$ \\
\hline Vesuvius & 1944 & $\mathrm{VM}$ & 44 & $30 / 32$ & $30 \pm 11$ & $19-41$ & $19 / 27$ & $49 \pm 25$ & $37-61$ & $41 \pm 25$ & $32-50$ \\
\hline \multicolumn{12}{|c|}{ Pyroclastic Lithic Clasts } \\
\hline Láscar & 1993 & LV & 24 & $42 / 50$ & $42 \pm 35$ & $33-51$ & $36 / 46$ & $23 \pm 5$ & $21-25$ & $46 \pm 27$ & $38-54$ \\
\hline Mount St. Helens & 1980 & $\mathrm{M}$ & 55 & $52 / 55$ & $50 \pm 27$ & $40-60$ & $0 / 68$ & $\ldots$ & $\ldots$ & $45 \pm 27$ & $38-52$ \\
\hline
\end{tabular}

${ }^{a}$ Deduced from the International Geomagnetic Reference Field (IGRF), the fields for the 1729-1900 flows were calculated using the GUFM model [Jackson et al., 2000]. The GUFM model assumes a $15 \mathrm{nT} / \mathrm{yr}$ decrease in dipole moment in its pre-1840 intensity estimates, which is now thought to be too high [Gubbins et al., 2006].

${ }^{\mathrm{b}}$ The number of successful samples is the numerator; the denominator is the total number of samples considered.

${ }^{\mathrm{c}}$ Average excludes the consistently high 1845 data.

\subsubsection{Synthetic Samples Glass Samples}

[40] The three synthetic glass samples were induced with a TRM in a field of $125.7 \mu \mathrm{T}$, and the MD sample $\mathrm{W}(11 \mu \mathrm{m})$ in a field of $100.5 \mu \mathrm{T}$. The three glass samples yielded Preisach paleointensity estimates of $119 \pm 3 \mu \mathrm{T}$ (GS3), $135 \pm 3 \mu \mathrm{T}$ (GS5) and $149 \pm 3 \mu \mathrm{T}$ (GS6). For the MD sample $\mathrm{W}(11 \mu \mathrm{m})$, the Preisach paleointensity method produced an estimate of $22 \pm 2 \mu \mathrm{T}$. To make this latter determination the number of hysterons was increased from $2 \times 10^{6}$ to $4 \times 10^{6}$. For these more MD-like samples, a higher number of hysterons is required to produce a consistent, repeatable estimate because a smaller proportion of the Preisach distribution lies within the memory region.

\subsubsection{Basaltic Lavas}

[41] Only a few samples were considered for each individual flow unit from Iceland (Table 2 and Data Set S1). As the basaltic lavas were relatively fresh material with strong signals, this led to relatively little data rejection (Table 2). The Preisach paleointensity estimates for the Hekla flows show a degree of scatter around the expected value of $52 \mu \mathrm{T}$, with the 1845 A.D. flow displaying a large overestimate. Excluding the anomalous 1845 A.D. data, the results from the Hekla lavas from the different flow units have also been averaged (Table 2); the field during the eruptions (1845-2000 A.D.) did not vary more than $1 / 2 \mu \mathrm{T}$ from $52 \mu \mathrm{T}$ [Jackson et al., 2000]. The average of the flows determined from 29 samples, is close to the expected value, with the mean producing an estimate of $51 \pm 21 \mu \mathrm{T}$, with a $\mathrm{CI}_{95}$ of $44-58 \mu \mathrm{T}$ (Table 2). The average estimate for the 1981 flow from Krafla is close to the expected value of $52 \mu \mathrm{T}$. The 1745 A.D. unit is much lower at $34 \pm 3 \mu \mathrm{T}$ compared to an expected field of $52 \mu \mathrm{T}$ (note that field model estimates of the intensity before 1840 A.D. carry an added uncertainty [Finlay, 2008]). With the exception of the 1922 AF flow (the Mývetningahraun lava flow), the estimates from Askja were all close to the expected value of $49.5 \mu \mathrm{T}$ (Table 2). For example, the 1961 flow returned an average of $52 \pm 20 \mu \mathrm{T}$ and the AC flow $50 \pm 22 \mu \mathrm{T}$. The average for all the Askja data including the AF flow, yields an average of $51 \pm 32 \mu \mathrm{T}\left(\mathrm{CI}_{95}\right.$ of $\left.43-59 \mu \mathrm{T}\right)$.

[42] Of the 25 samples from Paricutin, Mexico, 23 were of sufficient quality to make paleointensity estimates. On average the estimates are significantly above the expected value of $45 \mu \mathrm{T}$ (Table 2). Similarly, only two samples were rejected from the basaltic lavas from the 1944 eruption of Vesuvius. The paleointensity estimates from Vesuvius are lower than the expected field of $44 \mu \mathrm{T}\left(30 \pm 11 \mu \mathrm{T}, \mathrm{CI}_{95}\right.$ of $19-41 \mu \mathrm{T})$.

[43] Of the samples shown in Figure 3, H00KY (Figure 3c) and VM1DX (Figure 3d) yield accurate estimates of the paleointensity, $50 \pm 4 \mu \mathrm{T}$ and $46 \pm 1 \mu \mathrm{T}$, respectively, while P2EX (Figure 3a) produces an overestimate $(81 \pm 2 \mu \mathrm{T})$ (see Data Set S1).

\subsubsection{Pyroclastic Lithic Clasts}

[44] The pyroclastic lithic clasts displayed more complex AF demagnetization spectra, and not all the samples were accepted for Preisach paleointensity determination (Table 2), although all the samples considered had been emplaced above ambient temperature [Paterson et al., 2010c]. The quality of the FORC diagrams was generally good, though some samples were relatively noisy and had to be rejected.

[45] The mean paleointensity estimate from 42 samples from Volcán de Láscar was $46 \pm 35 \mu \mathrm{T}\left(\mathrm{CI}_{95}=33-51 \mu \mathrm{T}\right)$ 
(a) Arai plot for GS6

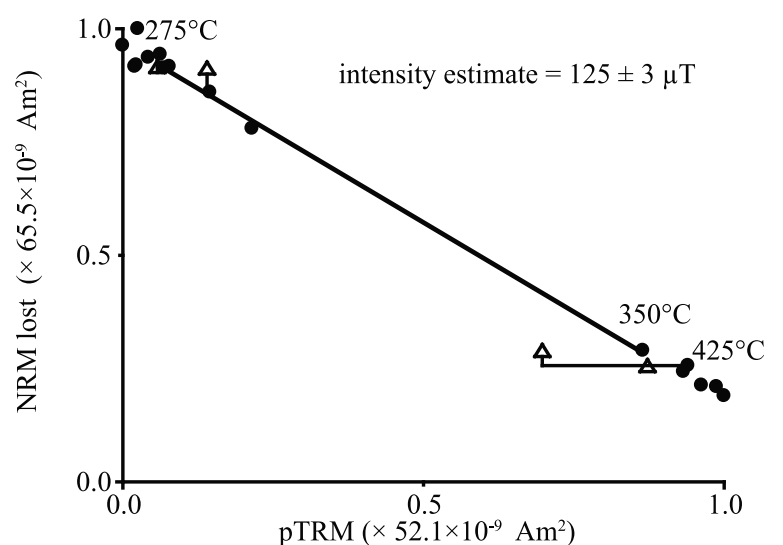

(b) Arai plot for $W(11 \mu \mathrm{m})$

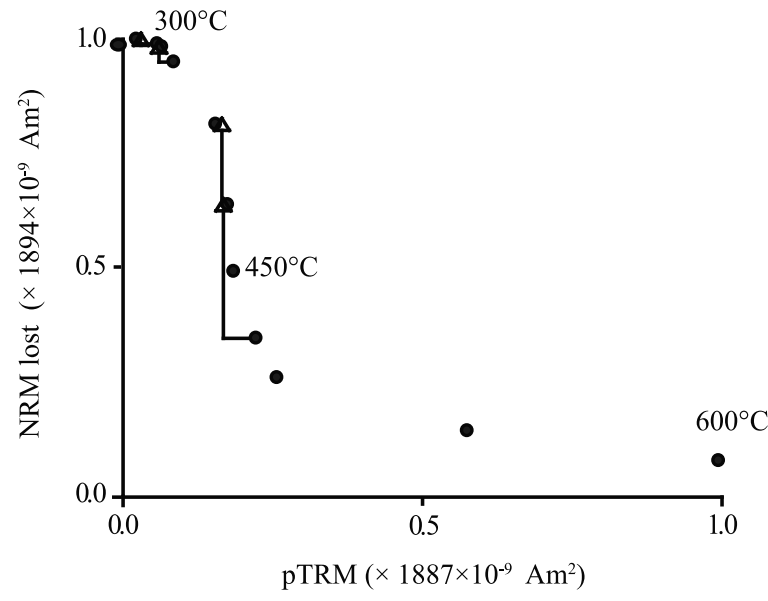

Figure 6. Arai plots for synthetic samples: (a) glass sample GS6 that passed at the ThellierTool B criteria level (see Appendix A) and (b) synthetic sample W $(11 \mu \mathrm{m})$ that failed to yield a paleointensity estimate, using the criteria detailed in Appendix A.

compared to an expected value of $24 \mu \mathrm{T}$. The samples from the 1980 Mount St. Helens eruption yield a mean of $50 \pm$ $27 \mu \mathrm{T}\left(\mathrm{CI}_{95}=40-60 \mu \mathrm{T}\right)$ from 52 samples, compared to an expected value of $55 \mu \mathrm{T}$. Sample LV11A (Figure 3b) yielded an overestimate of $30 \pm 1 \mu \mathrm{T}$ (see Data Set S1).

\subsection{Thellier-Type Paleointensity Estimation}

[46] For comparison to the Preisach paleointensity experiments, we consider Thellier-type paleointensity determinations on sister samples collected from the same flow units. All the determinations were analyzed using the ThellierTool 4.1 software [Leonhardt et al., 2004], applying the rigorous default quality criteria (see Appendix A for details). The new data from the synthetic samples and the lavas from Mexico and Italy are tabulated in Table A1 in Appendix A. We choose the default criteria over those newly proposed by Paterson et al. [2010a] as the purpose of the Thellier-type paleointensity estimates in this paper is purely for comparison.

\subsubsection{Synthetic Samples}

[47] Thellier estimates were made for the three synthetic glass samples initially induced with a thermoremanence in a field of $125.7 \mu \mathrm{T}$. These gave estimates of $118 \pm 4 \mu \mathrm{T}$ (GS3), $104 \pm 3 \mu \mathrm{T}$ (GS5) and $125 \pm 3 \mu \mathrm{T}$ (GS6, Figure 6a), all with the class " $\mathrm{B}$ " criteria (Table 1A). These are a few under the expected value; however, the samples were magnetically weak, and their signals were close to the measurement limit of the Orion VSM, giving rise to noisy Arai plots [Nagata et al., 1963] (Figure 6a). The samples had sharp unblocking spectra.

[48] The synthetic MD sample W $(11 \mu \mathrm{m})$ was induced with a TRM in a field of $100.5 \mu \mathrm{T}$. The Thellier method does not yield a reliable estimate (Figure 6b), failing to pass the minimum acceptability criteria.

\subsubsection{Basaltic Lavas}

[49] Thellier-type paleointensity determinations were made as part of this study for the Mexican and Italian lavas using the protocol described by Leonhardt et al. [2003]. Thellier-type paleointensity estimates for the Icelandic lavas from Hekla (flows 2000, 1980, 1913 and 1878 A.D.) and the 1729 A.D. flow from Krafla were reported in a previous study [Michalk et al., 2008]. The previous study employed the IZZI protocol [Yu et al., 2004]. Both applied protocols included pTRM checks [Coe, 1967] to monitor changes in the capacity of the specimen to acquire a pTRM and alteration during laboratory treatment. Furthermore, pTRM tail checks [Bol'shakov and Shcherbakova, 1979; Walton, 1984] were used to test if the pTRM gained is completely removed by reheating to the same temperature step in zero field to estimate the importance of MD remanence. A laboratory field of $50.4 \mu \mathrm{T}$ was used in the experiments carried out as part of this study, and $51.1 \mu \mathrm{T}$ by Michalk et al. [2008]. In both cases the field was applied during both heating and cooling.

[50] Average results from Mexico, Italy and Iceland are summarized in Table 2, and representative Arai plots for the new data from Mexico and Italy are shown in Figure 4. No Thellier-type experiments were carried out on samples from Askja.

[51] The samples from the 1943 eruption of Paricutin, Mexico, produce relatively accurate paleointensity estimates (Figure 7a) in agreement with previous studies [UrrutiaFucugauchi et al., 2004]. Of the 41 samples measured, 29 passed the default category B ThellierTool selection criteria, yielding an arithmetic average of $49 \pm 12 \mu \mathrm{T}$ and a $\mathrm{CI}_{95}$ of $44-54 \mu \mathrm{T}$. These estimates lie close to the actual value of $45 \mu \mathrm{T}$.

[52] Of the 27 samples from the 1944 eruption of Vesuvius, Italy, 18 passed the default category B ThellierTool selection criteria. These samples generally displayed less ideal behavior during the experiment (Figures $7 \mathrm{~b}$ ), giving a wide scatter of values, which is reflected in the large standard deviation of the mean (Table 2). The mean was $49 \pm 25 \mu \mathrm{T}$ and $\mathrm{CI}_{95}$ was $37-61 \mu \mathrm{T}$. The actual field value was $44 \mu \mathrm{T}$.

[53] The Icelandic paleointensities have been reported previously [Michalk et al., 2008]. The results are repeated in Table 2. The number of samples measured per flow unit was much smaller than those for Paricutin and Vesuvius giving rise to wide $\mathrm{CI}_{95}$ ranges. The lavas from Hekla, Iceland, from the different flow units have been averaged together to give a mean of $50 \pm 10 \mu \mathrm{T}$ compared to an expected value of $52 \mu \mathrm{T}\left(\mathrm{CI}_{95}=43-57 \mu \mathrm{T}\right)$. The 1745 A.D. flow of Krafla failed to yield a single reliable paleointensity estimate from the four measured samples.

\subsubsection{Pyroclastic Lithic Clasts}

[54] All the Thellier-type paleointensity estimates for the pyroclastic lithic deposits have been previously reported in 

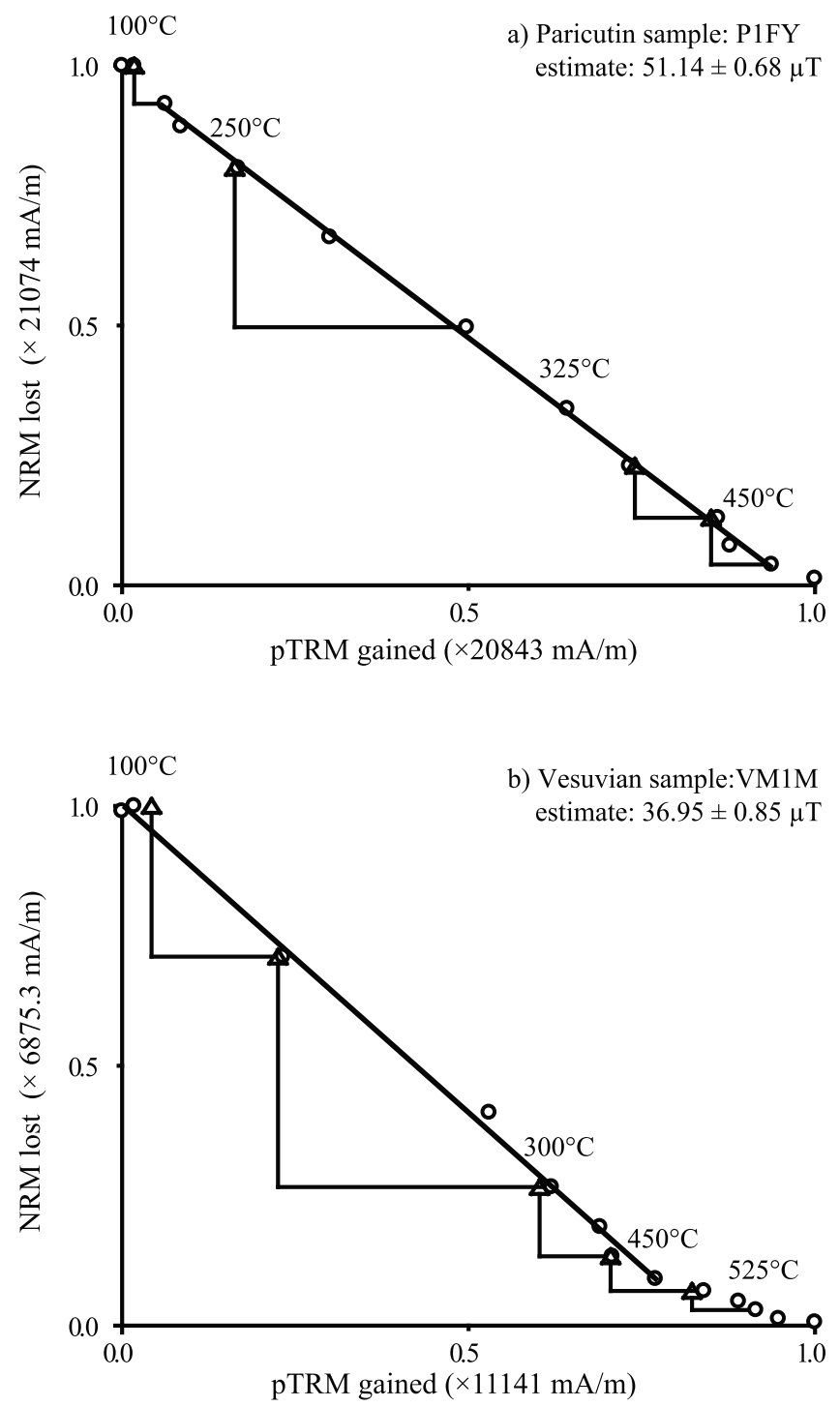

Figure 7. Representative Arai plots for samples (a) from Paricutin and (b) from Vesuvius. Arai plots for the lava samples from Hekla and Krafla have been shown in previous studies [Michalk et al., 2008], similarly for the pyroclastic lithic deposits [Paterson et al., 2010b]. The linear fitting was made using the ThellierTool's default B criteria (see Appendix A).

the study of Paterson et al. [2010b]. Paterson et al. [2010b] included both pTRM checks and pTRM tail checks. Here we refer directly to their data.

[55] For consistency with section 4.3.2 we consider results that passed the ThellierTool B default selection criteria; that is, we reanalyzed the raw data.

[56] The results from Volcán de Láscar were highly successful, yielding an estimate of $23 \pm 5 \mu \mathrm{T}\left(\mathrm{CI}_{95}=21-25 \mu \mathrm{T}\right)$ compared to an expected value of $24 \mu \mathrm{T}$ (Table 2). In comparison the results from the Mount St. Helens pyroclastic deposits yielded not a single estimate from 68 samples (Table 1). The samples from Mount St. Helens were particularly prone to alteration on heating [Paterson et al., 2010b], although the influence of experimental procedure (low laboratory to natural field strength) could not be excluded as a contributing factor that may have enhanced the influence of MD grains.

\subsection{REM Paleointensity Estimation}

[57] The averaged REM paleointensity estimates are tabulated in Table 2. Large variations in the NRM/SIRM ratios give rise to large standard deviations for the mean values and wide confidence limits. For the REM estimations, the same samples that were selected for the Preisach protocol paleointensity analysis were analyzed.

\subsubsection{Synthetic Samples}

[58] The three glass samples yielded high estimates for the intensity: GS3 was $582 \mu \mathrm{T}, \mathrm{GS} 5586 \mu \mathrm{T}$ and GS6 $566 \mu \mathrm{T}$, compared to an expected value of $125.7 \mu \mathrm{T}$. In contrast, MD sample $\mathrm{W}(11 \mu \mathrm{m})$ returned a value of $51 \mu \mathrm{T}$, when induced with a field of $100.5 \mu \mathrm{T}$.

\subsubsection{Basaltic Lavas}

[59] The REM values for the lavas are on average higher than the expected values (Table 2, individual estimates in Data Set S1), with the REM method for Paricutin giving a paleointensity estimate of $165 \pm 60 \mu \mathrm{T}\left(\mathrm{CI}_{95}=139\right.$ $191 \mu \mathrm{T})$; however, the Vesuvian REM estimate is closer to the expected value of $44 \mu \mathrm{T}$, at $41 \pm 25 \mu \mathrm{T}$. Twenty samples from the Kvíslahraun (AC) flow of Askja yielded an average of $52 \pm 9 \mu \mathrm{T}\left(\mathrm{CI}_{95}=48-56 \mu \mathrm{T}\right)$ compared to an expected value of $49.5 \mu \mathrm{T}$. The average for all the Hekla samples (excluding the 1845 A.D. flow) is $71 \pm 20 \mu \mathrm{T}\left(\mathrm{CI}_{95}=62\right.$ $80 \mu \mathrm{T})$, and for all the Askja samples $72 \pm 50 \mu \mathrm{T}\left(\mathrm{CI}_{95}=\right.$ 60-84 $\mu \mathrm{T})$.

[60] Of the samples shown in Figure 3, H0OKY (Figure 3c) yields an accurate estimate of the paleointensity $(47 \mu \mathrm{T}), \mathrm{VM} 1 \mathrm{DX}$ (Figure $3 \mathrm{~d})$ is a little high $(70 \mu \mathrm{T})$, and P2EX (Figure 3a) produces a large overestimate $(202 \mu \mathrm{T})$ (Data Set S1).

\subsubsection{Pyroclastic Lithic Clasts}

[61] The REM estimates for Volcán de Láscar are roughly twice the expected value at $46 \pm 27 \mu \mathrm{T}$ compared to the known field of $24 \mu \mathrm{T}$; however, the Mount St. Helens REM values are closer to the true field (Table 2). None of the $95 \%$ confidence intervals for these samples include the known field intensity. Sample LV11A (Figure 3c) yielded an overestimate of $44 \mu \mathrm{T}$ (Data Set S1).

\section{Discussion}

[62] The Preisach paleointensity estimates are summarized in Table 2. Generally the Preisach paleointensity estimates for the Icelandic lavas are accurate, e.g., the average for Askja (mean $51 \pm 32 \mu \mathrm{T} \mathrm{CI}_{95}=43-59 \mu \mathrm{T}$, expected field $49.5 \mu \mathrm{T}$ ), though some suites of samples are seen to over or underestimate the known field, e.g., the lava from the 1944 eruption of Vesuvius (mean $30 \pm 11 \mu \mathrm{T}$, expected field $44 \mu \mathrm{T}$ ). The 1845 A.D. flow from Hekla overestimated the field significantly (Table 2); however, only six samples were considered.

[63] Taking the average across the whole data set where the actual field was known at the time of eruption, i.e., the post-1840 A.D. data, yields an average normalized paleointensity estimate, i.e., paleointensity/actual field, from 248 samples of $1.19 \pm 0.84\left(\mathrm{CI}_{95}=1.09-1.29\right)$. Ignoring the anomalous data from 1845 lava flow from Hekla and Volcán de Láscar yields an average normalized paleo- 


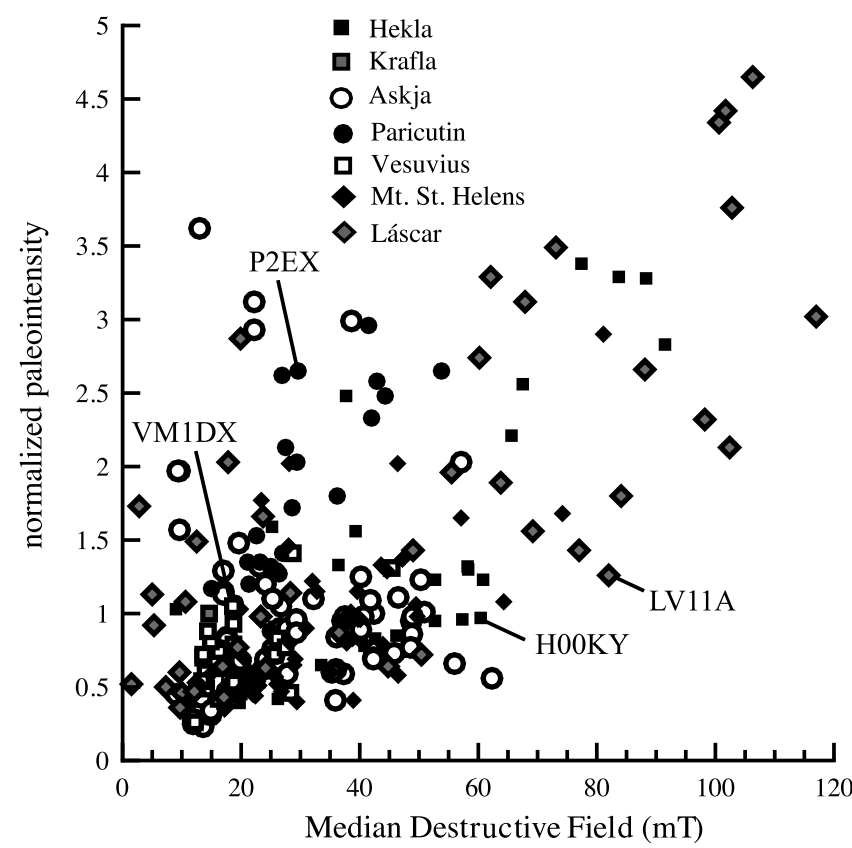

Figure 8. Preisach-derived paleointensity estimates plotted against the median destructive field (MDF) for the seven suites of samples considered in this study. The four natural samples (P2EX, H00KY, LV11A, and VM1DX) are highlighted. The Hekla samples that display high MDF values all come from the 1845 A.D. flow.

intensity estimate $1.02 \pm 0.2\left(\mathrm{CI}_{95}=0.93-1.11\right)$ from 200 individual estimates. The basalts alone yielded an average of $1.13 \pm 0.7\left(\mathrm{CI}_{95}=1.00-1.26\right)$ from 154 samples out of 168 measured $\left(1.06 \pm 0.65\left(\mathrm{CI}_{95}=0.96-1.16\right)\right.$ if the 1845 A.D. Hekla data is rejected.). The post-1845 A.D. Icelandic samples yield an average of $1.01 \pm 0.6\left(\mathrm{CI}_{95}=\right.$ 0.89-1.13) from 95 samples. The pyroclastic lithic suites samples display differing behavior: the Mount St. Helens samples yield a small underestimate of $0.90 \pm 0.51\left(\mathrm{CI}_{95}=\right.$ 0.86-1.04) from 52 samples, but the Láscar samples a large overestimate (1.76 $\pm 1.23\left(\mathrm{CI}_{95}=1.39-2.13\right), 42$ samples $)$. That the average over such large data sets is close to unity and that most of $\mathrm{CI}_{95}$ ranges include 1.0, suggests that protocol is essentially correct, although there may be some systematic overestimate in the calculation given that the mean is $>1.0$. These distributions have very large standard deviations; however, the large number of measured points reduces $\mathrm{CI}_{95}$ to relatively narrow ranges.

\subsection{Preisach Paleointensity Method and Domain State}

\subsubsection{Synthetic Samples}

[64] The three synthetic glass samples, which are essentially SD in character (Figures 2 and 4), return Preisach paleointensity estimates close to the expected value, the average of these three is $135 \pm 15 \mu \mathrm{T}$ (inducing field was $125.5 \mu \mathrm{T})$. The samples were particularly magnetically weak, and the measured FORC diagrams were subject to significantly more noise than the other FORC diagrams measured as part of this study. This is a possible cause of deviations from the expected value. The sample GS6 that displayed the least SD-like hysteresis parameters (Figure 2), also yielded an intensity estimate furthest from the expected value.
[65] The MD sample W $(11 \mu \mathrm{m})$ (Figures 2 and 5), produced a paleointensity estimate of $22 \pm 2 \mu \mathrm{T}$, which is a large underestimate for an expected field value of $100.5 \mu \mathrm{T}$. The Thellier-type method also failed to yield a reliable estimate (Figure 6).

[66] The results for the synthetic samples are unsurprising, i.e., the Preisach paleointensity method worked well for the SD-like samples but poorly for the MD-like sample. This is because there are theoretical limitations on the application of the Preisach paleointensity method to MD samples, as the method is based on energy barriers derived for randomly orientated, single-domain Stoner-Wohlfarth particles [Muxworthy and Heslop, 2011].

\subsubsection{Natural Samples}

[67] To examine domain state within our natural samples, we consider two sets of parameters: (1) the median destructive field (MDF) derived from the AF demagnetization of the NRM, which we plot against the normalized Preisach paleointensity (Figure 8), and (2) the Day plot, which depicts the reduced remanent saturation, $M_{R S} / M_{S}$, against $H_{C R} / H_{C}$ (Figure 9.) The Day plot is a standard diagram for identifying domain state; however, it does not necessarily define the remanence carriers nor does it necessarily accurately describe a domain state, as can be seen by comparing the FORC diagram for sample LV11A (Figure $3 b$ ) with its position on the Day plot (Figure 2); its position on the latter plot belies its more complex domain state distribution. In contrast, the MDF examines only the remanence carriers. It is typically smaller for MD grains than SD grains and has been suggested as a selection criterion for paleointensity measurements [Carvallo et al., 2006].

[68] In Figure 8 we plot normalized paleointensity versus MDF. Generally, most of the samples cluster between MDF values of 10 and $50 \mathrm{mT}$ with normalized paleointensity values close to unity; however, there are a number of samples from Hekla and Láscar, and to a lesser extent Paricutin, with very high MDF values that appear to display a loose relationship between increasing MDF and paleointensity (over)estimate. The Hekla samples that display these high MDF values all come from the 1845 A.D. flow. If MDF is used as a selection parameter, using a cutoff MDF value of $50 \mathrm{mT}$, reduces the average normalized paleointensity across the entire data set from $1.19 \pm 0.84\left(\mathrm{CI}_{95}=\right.$ $1.09-1.29)$ to $0.98 \pm 0.61\left(\mathrm{CI}_{95}=0.90-1.06\right)$.

[69] In the Day plot (Figure 9) the paleointensity data are represented by color (the size of the symbol is inversely related to the standard deviation). There is no overall relationship between a natural sample's position on the Day plot and the paleointensity estimate. The four synthetic samples do appear to display such a trend, i.e., samples GS3 and GS5 with the most SD-like hysteresis properties return more accurate paleointensity estimates than GS6 and W $(11 \mu \mathrm{m})$.

[70] Highlighted on Figure 9 are the Paricutin samples with $M_{R S} / M_{S}$ ratios near or above 0.5 , which yield high estimates with large associated errors. Such high $M_{R S} / M_{S}$ ratios are rare for natural systems and may indicate in situ postacquisition chemical alteration and chemical remanent acquisition (CRM). Evidence for this is supported by ore microscopy observations, which found that samples associated with both high MDF values, $M_{R S} / M_{S}$ ratios and high paleointensity estimates displayed more evidence for low-temperature oxi- 


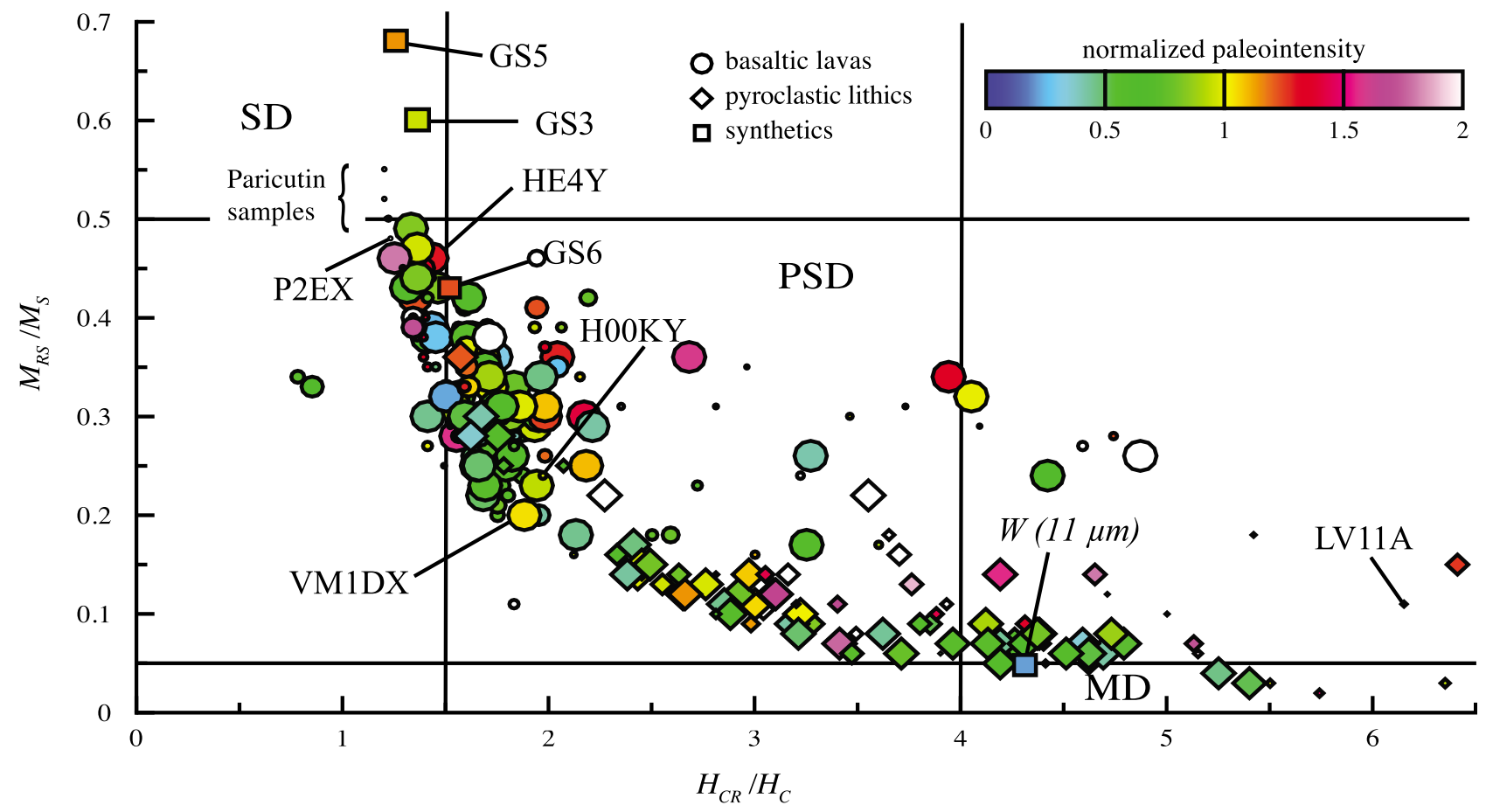

Figure 9. A Day plot of the hysteresis parameter ratios, where the individual symbol color indicates the normalized paleointensity estimate, and symbol size is inversely associated with the paleointensity estimate error, i.e., the bigger the symbol, the smaller the error associated with the estimate. The samples are split into three groupings: (1) synthetic samples, (2) natural lavas, and (3) natural pyroclastic lithics. The data set is smaller than in Figure 2, as some samples failed to yield paleointensity estimates. The synthetic samples and four natural samples (P2EX, H00KY, LV11A and VM1DX) are highlighted. The Paricutin samples that displayed high $M_{R S} / M_{S}$ ratios and large overestimates of the paleointensity are also highlighted.

dation. Therefore, it is suggested that the overestimates in the Paricutin samples are likely due to chemical alteration.

\subsection{Preisach Paleointensities and the Importance of Cooling Rate}

[71] Varying the cooling rate is known to affect the resultant TRM intensity [e.g., McClelland-Brown, 1984]. In the Preisach paleointensity estimates (section 4.3), a total cooling time of 30 days was used, i.e., 30 days to cool from the Curie temperature to within $1 \%$ of the ambient temperature using Newtonian cooling [Muxworthy and Heslop, 2011]. This length of time is of the correct order of magnitude for the type of material considered in this paper [Halgedahl et al., 1980]; however, other environments can experience much longer or shorter cooling times.

[72] In the calculation of the thermoremanence in the model [Muxworthy and Heslop, 2011], we have used the total external field which is a summation of both the applied field and the local interaction field [Muxworthy and Heslop, 2011, equations (13) and (14)], previous TRM models did not include the local interaction field term [Dodson and McClelland-Brown, 1980; Halgedahl et al., 1980]. In addition, previous models determined the equilibration time $t_{e q}$ by taking discrete time intervals, whereas the Preisach paleointensity method in this study uses an analytical expression for $t_{e q}$ obtained by numerically solving the master equation [Spinu et al., 2001; Borcia et al., 2002].
[73] We investigate the contribution of these differences in Figure 10, where we have calculated the mean predicted TRM intensity (normalized by the SIRM) for the samples from Hekla for three models: (1) the model as described by Muxworthy and Heslop [2011], (2) the same model, but with equilibration time $t_{e q}$ determined by taking discrete time intervals identical to that of Dodson and McClelland-Brown [1980] and Halgedahl et al. [1980], and (3) the same model of Muxworthy and Heslop [2011] but with the local interaction field set to zero in equation (14).

[74] The discrete calculation (model 2) yields almost identical TRM intensity estimates as the continuous model (model 1). There are small deviations between the two TRM intensity estimates, but these are within error of each other, and there is no clear difference in trend, i.e., TRM intensity decreases with increasing cooling time (Figure 10).

[75] In contrast, there are large differences between model 1 and 3. Without the local interaction field in equation (14) the resultant TRM intensity is larger, but more importantly responds to changes in the cooling rate in the opposite sense. Without the local interaction field, model 3 yields the same trends as Dodson and McClelland-Brown [1980] and Halgedahl et al. [1980]; that is, increasing the cooling time leads to an increase in the TRM intensity. In contrast, for most samples, introducing interactions leads to the opposite effect; that is, the TRM intensity decreases with increasing cooling time. 


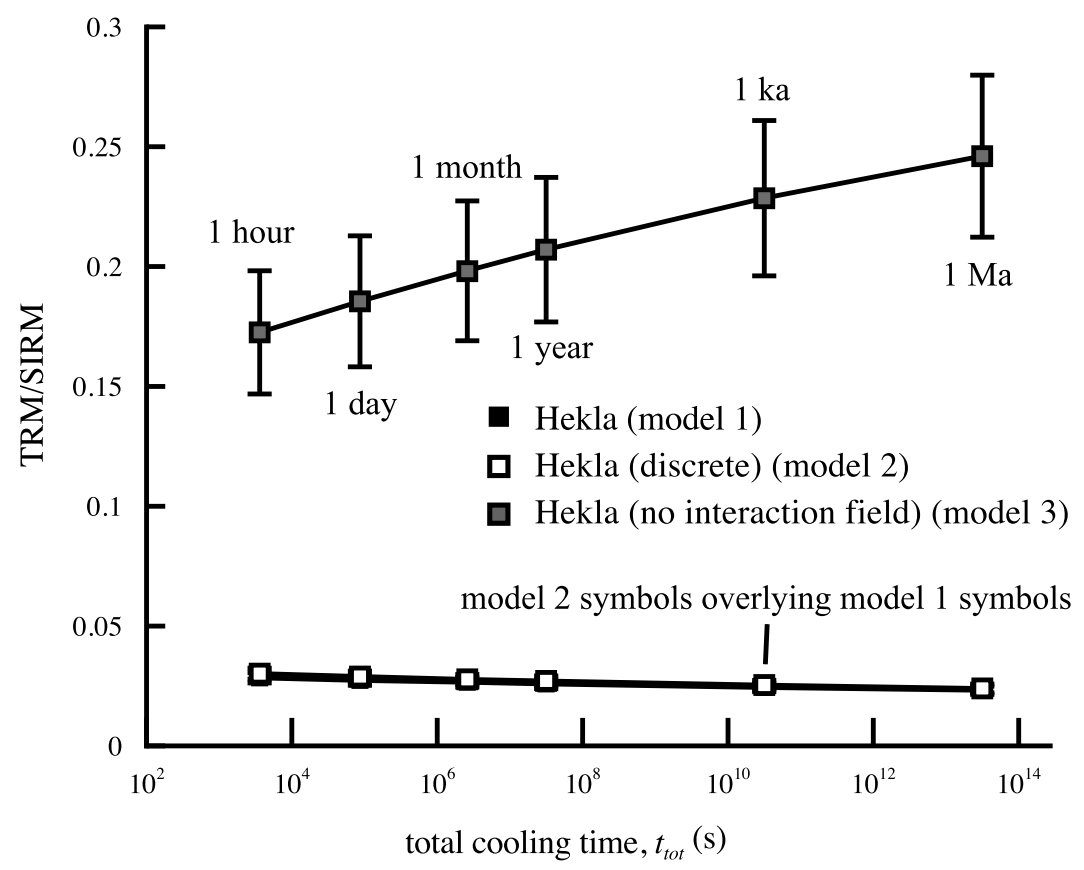

Figure 10. TRM/SIRM versus total cooling time for the samples from Hekla for the three models described in the text. The symbols from model 1 (the model used in this paper) are overlain by the results from model 2. The error bars span the $\mathrm{CI}_{95}$ interval. The error bars for the model 1 and model 2 values are smaller than the symbol size.

[76] This model response is not surprising and is clearly supported by experimental data: McClelland-Brown [1984] experimentally found that out of four samples, only one sample $(0.19 \%$ concentration, dispersed SD magnetite powder) displayed the same behavior as predicted by Dodson and McClelland-Brown [1980], but the remaining samples displayed the opposite trend, similar to that predicted by model 1 and model 2 (Figure 10). These samples consisted of the same SD magnetite dispersed at $2.14 \%$ concentration and two PSD titanomagnetite $\left(\mathrm{Fe}_{2.7} \mathrm{Ti}_{0.3} \mathrm{O}_{4}\right)$ samples with mean grain sizes of $2.3 \mu \mathrm{m}$ and $34 \mu \mathrm{m}$. McClelland-Brown [1984] attributed this disagreement for these three samples with the theory of Dodson and McClelland-Brown [1980] to magnetostatic interactions both intergrain and internal.

[77] In Figure 11, paleointensity as a function of cooling rate is plotted for the lavas from samples from Vesuvius, Hekla, Askja and Paricutin, and the pyroclastic deposits from Volcán de Láscar and Mount St. Helens. We exclude the Krafla data, as the data set is small. Increasing the total cooling time, $t_{\text {tot }}$, i.e., decreasing the cooling rate, decreases the predicted TRM intensity, which in turn increases the paleointensity estimate (Figure 11). The relationship between paleointensity and cooling rate is approximately logarithmic.

\subsection{The Importance of the Barbier Relationship}

[78] Key to the determination of the critical energy barriers is the use of the empirically derived Barbier relationship [Barbier, 1954; Wohlfarth, 1984] that is used in the proposed Preisach paleointensity method [Muxworthy and Heslop, 2011] to relate the thermal fluctuation field (and the activation volume) to the coercive force. In the Preisach paleointensity protocol we use the relationship derived specifically from basaltic lavas [Muxworthy et al., 2009], i.e., $\log H_{f} \approx 0.54 \log H_{C}-0.52$, where $H_{f}$ is thermal fluctuation field. Clearly, this is a potential source of error associated with the use of this relationship.

[79] To assess this possible source of error we systematically varied the gradient, i.e., 0.54 , and recalculated the linear relationship (in log space) by considering the mean of the experimental data reported by Muxworthy et al. [2009]. We allowed the gradient to vary between 0.1 and 1.1 and recalculated the Preisach paleointensity estimates for the all the natural data sets (Figure 12). With the exception of the results from Láscar and Paricutin, the results appear to be relatively invariant to relatively large variations in our Barbier relationship fit. The Láscar and Paricutin samples appear to display a slight increase of the mean paleointensity estimate with increasing gradient. This trend was repeatable. Examination of individual data revealed that this increase was particularly enhanced in samples such as LV11A (Figure $3 b$ ) that display very complex FORC distributions and plot beyond the usual regions of the Day plot (Figure 2).

\subsection{Comparison of the Preisach With the Thellier-Type and REM Estimates}

\subsubsection{Synthetic Samples}

[80] For the three glass SD-like samples, the Preisach and Thellier methods yielded similar paleointensity estimates. The average for the Preisach paleointensity protocol was $135 \pm 15 \mu \mathrm{T}$, and for the Thellier method $115 \pm 24 \mu \mathrm{T}$, i.e., both within $8 \%$ of the expected value of $125.7 \mu \mathrm{T}$. From these, albeit magnetically weak, SD samples, the Preisach paleointensity method appears to be just as reliable as the Thellier method for chemically stable samples. In contrast the REM method yielded a very large overestimate of $578 \pm$ $11 \mu \mathrm{T}$. 


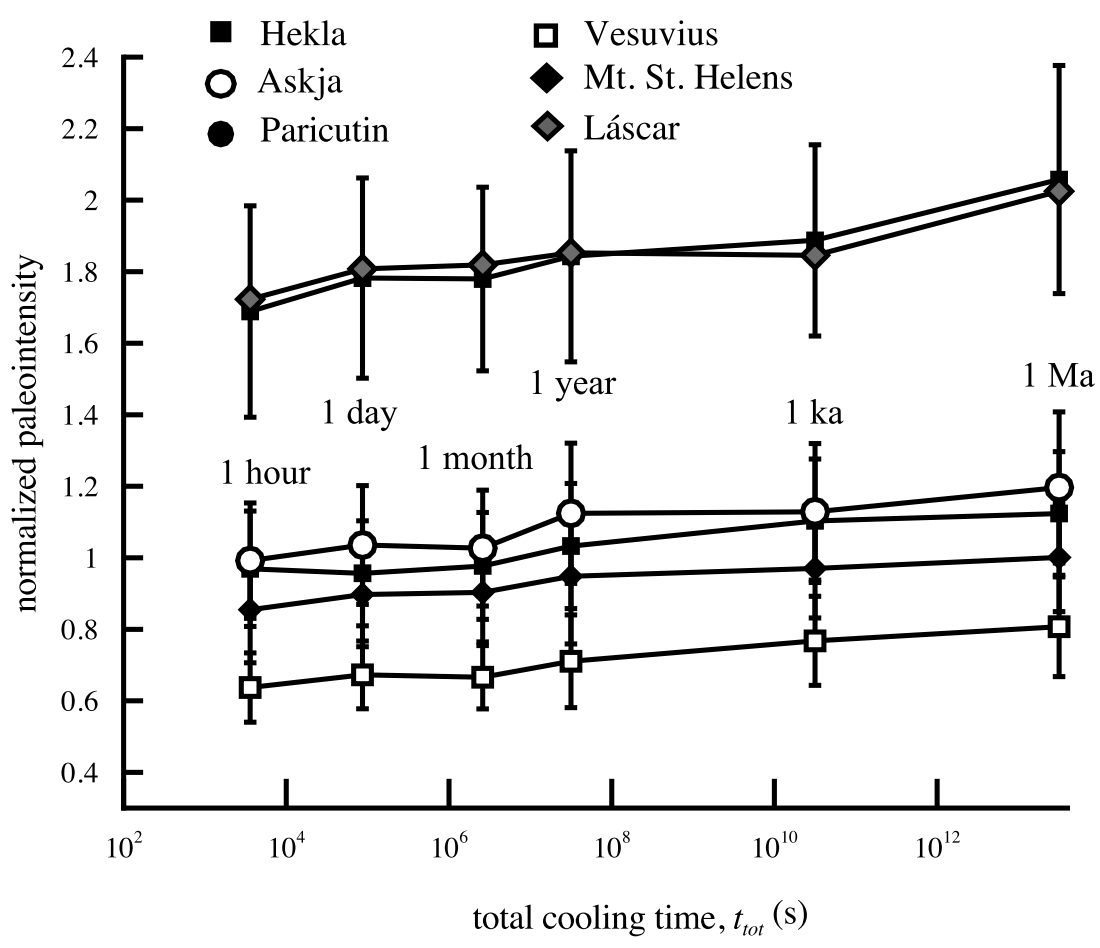

Figure 11. Normalized Preisach paleointensity estimates, i.e., paleointensity/actual field, as a function of total cooling time for the samples from Hekla, Askja, Paricutin, Vesuvius, Láscar, and Mount St. Helens. The error bars span the $\mathrm{CI}_{95}$ interval.

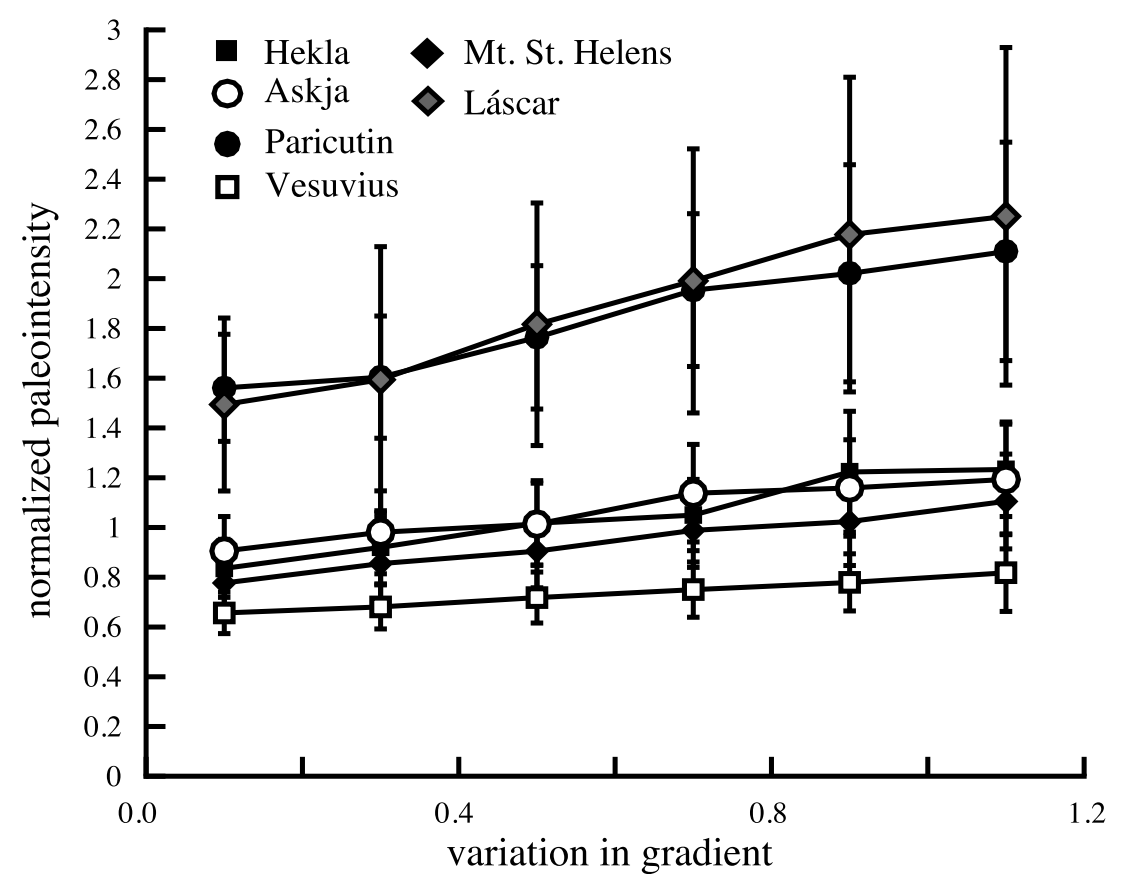

Figure 12. Variation in the gradient of the Barbier relationship, i.e., $\log H_{f} \approx 0.54 \log H_{C}-0.52$, versus returned Preisach paleointensity estimate for the samples from Hekla, Askja, Paricutin, Vesuvius, Láscar, and Mount St. Helens. The relationship is used in the Preisach paleointensity calculation and was empirically derived for basalts [Muxworthy et al., 2009]. The error bar is half the $\mathrm{CI}_{95}$ range. 

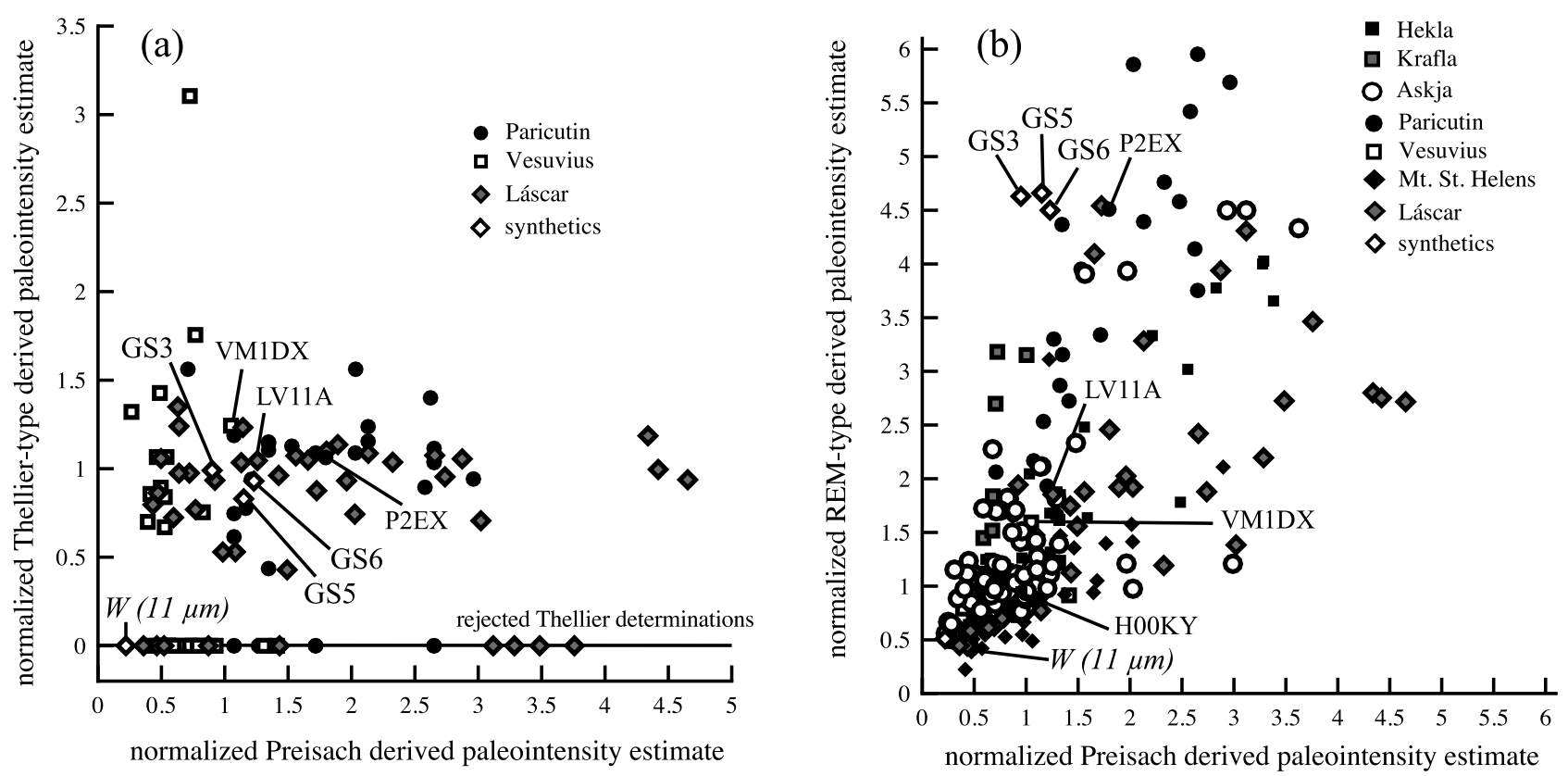

Figure 13. (a) Comparison of the Thellier-type paleointensity estimates versus the Preisach-derived paleointensity determinations for samples from Paricutin, Vesuvius, and Volcán de Láscar. The two different paleointensity determinations were made on samples from the same core in the case of lavas or from the same clast for the samples from Volcán de Láscar. Cores or clasts that yielded a Preisach paleointensity estimate but failed the criteria for a Thellier-type paleointensity estimate are assigned a Thellier-type estimate of zero and plotted on the $x$ axis. No rejection criteria have been applied to the Preisach data. (b) Comparison of the REM-type paleointensity estimates versus the Preisach-derived paleointensity determinations for all the samples considered in this study. Where measured, the four natural samples (P2EX, H00KY, LV11A, and VM1DX) are highlighted.

[81] The MD-like sample $\mathrm{W}(11 \mu \mathrm{m})$ failed to yield a Thellier estimate (Figure 6b), and the Preisach paleointensity estimate was $22 \pm 2 \mu \mathrm{T}$ compared to an expected value of $100.5 \mu \mathrm{T}$. The REM method underestimated the intensity of the inducing field returning a value of $51 \mu \mathrm{T}$ (induction field was $100.5 \mu \mathrm{T})$.

\subsubsection{Natural Samples}

[82] For the natural samples the Preisach, Thellier-type and REM paleointensity estimates are summarized in Table 2. In Figure 13a, Thellier-derived paleointensity estimates are plotted against the Preisach paleointensity estimates for samples from Vesuvius, Paricutin and Volcán de Láscar. The paleointensity estimates are compared for subsamples from the same core or clast. Both sets of paleointensity results show the statistical nature of paleointensity determination, and the importance of large sampling strategies [Biggin et al., 2003; Paterson et al., 2010a].

[83] Generally, the Preisach paleointensity estimates compare favorably with the Thellier-type results for "wellbehaved" samples; for example, for the Preisach and Thellier-type protocols the average for the Hekla samples was $51 \pm 21 \mu \mathrm{T} \mathrm{T}\left(\mathrm{CI}_{95}=44-58 \mu \mathrm{T}\right)$ and $50 \pm 10 \mu \mathrm{T}$ $\left(\mathrm{CI}_{95}=43-57 \mu \mathrm{T}\right)($ expected $52 \mu \mathrm{T})$, respectively, though there are cases where the Preisach method out-performed the Thellier-type method and vice versa. For example, the Thellier-type protocols used to make paleointensity estimates from the lithic clasts from Mount St. Helens, failed to yield a single paleointensity estimate from 68 samples
[Paterson et al., 2010b]. In contrast, the Preisach paleointensity method produced a mean of $50 \pm 27 \mu \mathrm{T}$ $\left(\mathrm{CI}_{95}=40-60 \mu \mathrm{T}\right)$ (Table 2$)$. This is slightly lower than the expected value, though the expected value falls with the error range. Similarly, the Preisach paleointensity method was able to make estimates for the flows from Krafla, which both have very low Curie temperatures (Table 1); the 1981 estimate being very close to the expected value. It is often difficult to apply Thellier-type methods to samples with such low Curie temperatures.

[84] In contrast, for the samples from the Vesuvius lavas and the Volcán de Láscar lithics, the Thellier-type method returns more reliable paleointensity estimates. For Vesuvius the Preisach paleointensity protocol underestimated the field by $\sim 33 \%$ determined from 23 measurements (Table 2), whereas as the Thellier method overestimated the field by only $4 \mu \mathrm{T}$. The samples from Vesuvius displayed significant chemical alteration during the Thellier-type experiments and the Thellier-type paleointensity estimates were extracted from relatively low-temperatures (Table A1). For the Volcán de Láscar lithics, the Preisach paleointensity estimate returns an estimate $76 \%$ greater than the expected value. The Thellier method return $23 \pm 5 \mu \mathrm{T}$ compared to an actual field value of $24 \mu \mathrm{T}$.

[85] These differences may have to do with the rejection rates, as the rejection rate for the Thellier-type determinations is higher than the Preisach paleointensity estimates (Table 2). There are two main reasons for this: first, the 

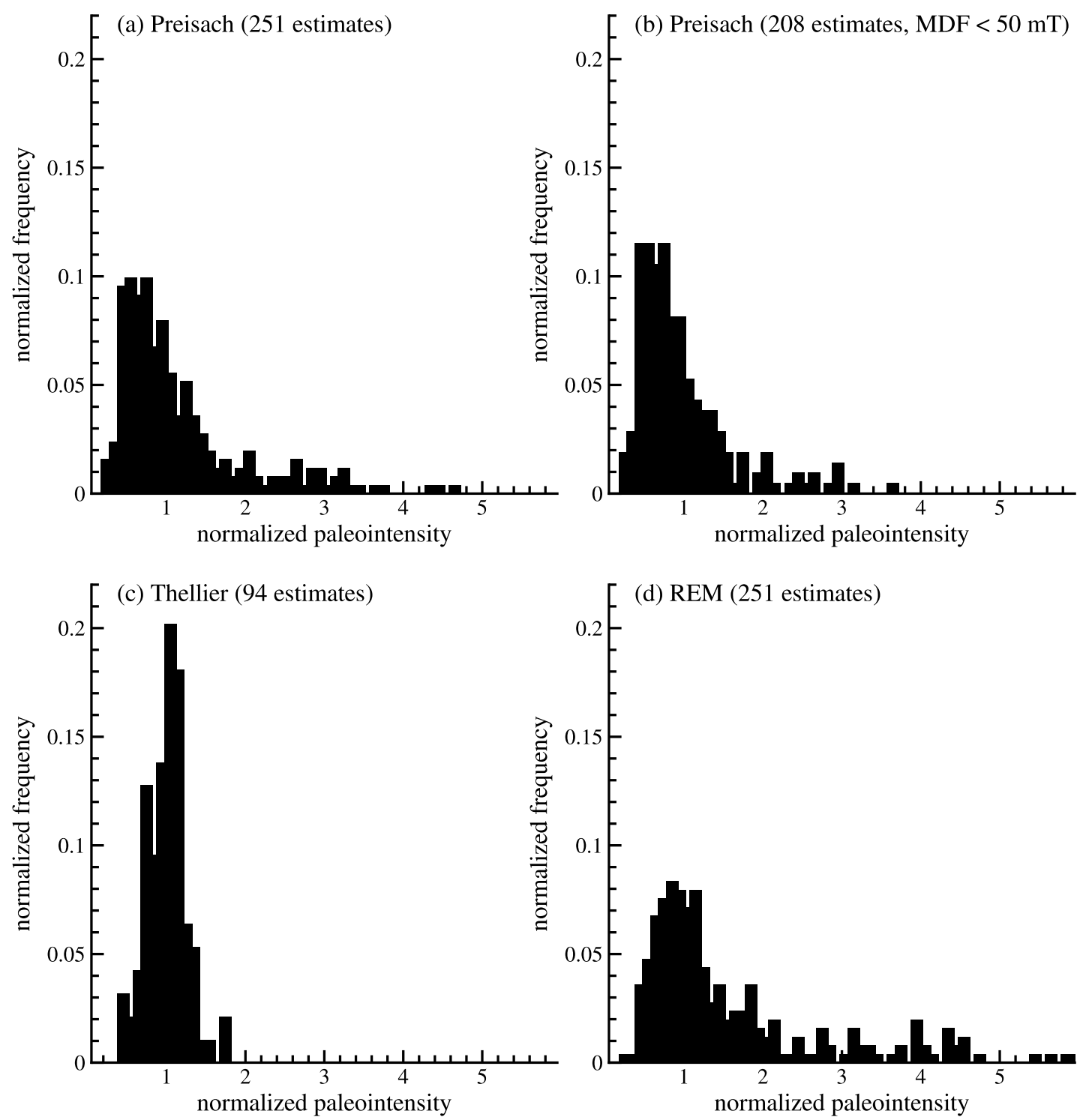

Figure 14. Frequency histograms of the normalized paleointensity data for (a) all the Preisach estimates, (b) the Preisach estimates for samples with an MDF $<50 \mathrm{mT}$, (c) the Thellier data, (d) the REM data.

Preisach-based approach is nonheating so samples will not be rejected as a result of chemical alteration during the experiment, and second, Thellier-type protocols have been studied and refined for many decades. There are now many reasons for rejecting data, e.g., pTRM tail checks, which were not part of the original experimental design. The Preisach paleointensity method is new and perhaps in the future, new protocols will be developed for rejecting data. For example, consider the MDF rejection criteria tentatively proposed in section 5.1.2, if we apply these rejection criteria to Volcán de Láscar samples, the Preisach paleointensity estimate reduces from $42 \pm 35 \mu \mathrm{T}\left(\mathrm{CI}_{95}=33-51 \mu \mathrm{T}\right)$ to $24 \pm$ $15 \mu \mathrm{T}\left(\mathrm{CI}_{95}=18-30 \mu \mathrm{T}\right)$. Yet the application of rejection criteria should be treated with caution, because although they may have the effect of reducing the relatively large spread in the data (Figure 13a) and the resulting standard deviations (Table 2), they have the potential to bias the mean estimate at the expense of reducing the error. If the observed variation in paleointensity estimates are truly random, and not biased by an effect, e.g., induction of growth chemical remanent magnetization, the introduction of new rejection criterion may be counter productive.

[86] The REM paleointensity estimates are plotted against the Preisach estimates in Figure 13b. In agreement with the results for synthetic samples, the Preisach paleointensity estimates are lower than the REM estimates, and there is considerably greater spread in the REM estimates, with the REM overestimating the field by over six times for some samples. Comparing the mean values, the Preisach paleointensity estimates are considerably closer on average to the actual field (Table 2). The main exception to the second point is the estimates from Vesuvius, where the REM produces a considerably better paleointensity estimate. That the REM estimates are consistently much higher than the actual field intensities, suggests that the calibration factor may be 
Table A1. The Thellier Results Measured for This Study ${ }^{\mathrm{a}}$

\begin{tabular}{|c|c|c|c|c|c|c|c|c|c|c|c|}
\hline Sample & intensity $(\mu \mathrm{T})$ & $\pm \sigma(\mu \mathrm{T})$ & $\Delta T^{\mathrm{b}}\left({ }^{\circ} \mathrm{C}\right)$ & $N$ & $f$ & $g$ & $q$ & $w$ & $\delta(\mathrm{CK})$ & $\delta(\mathrm{TR})$ & class \\
\hline \multicolumn{12}{|c|}{ Paricutin 1943 A.D. eruption } \\
\hline $\mathrm{P} 1 \mathrm{CX}$ & 27.7 & 2.3 & $20-600$ & 14 & 0.93 & 0.86 & 9.6 & 2.8 & 6.3 & 4.4 & $\mathrm{~B}$ \\
\hline $\mathrm{P} 1 \mathrm{CY}$ & 33.6 & 0.5 & $325-600$ & 5 & 0.73 & 0.20 & 9.3 & 5.3 & 2.3 & 0.4 & $\mathrm{~A}$ \\
\hline $\mathrm{P} 1 \mathrm{CZ}$ & 53.5 & 0.8 & $20-375$ & 10 & 0.59 & 0.87 & 34.8 & 12.3 & 0.8 & 0.3 & A \\
\hline $\mathrm{P} 1 \mathrm{E}$ & 45.6 & 0.5 & $200-350$ & 7 & 0.51 & 0.82 & 39.2 & 17.5 & 0.7 & 6.0 & $\mathrm{~A}$ \\
\hline P1FX & 70.3 & 1.3 & $100-350$ & 8 & 0.31 & 0.80 & 13.4 & 5.5 & 0.1 & 1.4 & A \\
\hline P1FY & 51.1 & 0.7 & $200-500$ & 10 & 0.90 & 0.86 & 58.5 & 20.7 & 1.0 & 5.8 & A \\
\hline P1GA & 78.8 & 4.9 & $20-250$ & 7 & 0.46 & 0.70 & 5.2 & 2.3 & 1.8 & 5.0 & A \\
\hline P1GB & 53.7 & 0.9 & $150-250$ & 5 & 0.34 & 0.61 & 11.8 & 6.8 & 0.5 & 0.2 & A \\
\hline P1GC & 47.8 & 0.6 & $250-350$ & 5 & 0.54 & 0.73 & 32.1 & 18.5 & 2.8 & 0.3 & A \\
\hline $\mathrm{P} 1 \mathrm{H}$ & 50.7 & 1.1 & $100-275$ & 6 & 0.82 & 0.75 & 28.7 & 14.4 & 4.5 & 7.9 & A \\
\hline P1HB & 49.0 & 0.4 & $250-400$ & 6 & 0.57 & 0.79 & 49.9 & 25.0 & 4.5 & 0.7 & B \\
\hline P1KA & 51.8 & 0.4 & $20-550$ & 13 & 0.95 & 0.88 & 98.0 & 29.6 & 1.7 & 4.3 & A \\
\hline $\mathrm{P} 1 \mathrm{~KB}$ & 51.5 & 4.6 & $325-600$ & 5 & 0.6 & 0.36 & 2.4 & 1.4 & 5.7 & 0.5 & B \\
\hline $\mathrm{P} 1 \mathrm{KC}$ & 19.6 & 1.7 & $325-600$ & 6 & 0.43 & 0.69 & 3.4 & 1.7 & 6.5 & 4.3 & B \\
\hline P1KD & 49.7 & 1.0 & $20-250$ & 5 & 0.70 & 0.67 & 22.5 & 13.0 & 0.7 & 1.1 & A \\
\hline P1L & 34.9 & 1.3 & $20-225$ & 5 & 0.78 & 0.54 & 11.0 & 6.3 & 1.9 & 0.0 & A \\
\hline P1NA & 48.9 & 1.8 & $20-400$ & 10 & 0.91 & 0.83 & 20.9 & 7.4 & 3.3 & 5.8 & B \\
\hline P1O & 42.4 & 0.6 & $200-375$ & 8 & 0.63 & 0.80 & 37.0 & 15.1 & 1.4 & 2.1 & A \\
\hline P2AA & 50.1 & 0.4 & $100-350$ & 7 & 0.76 & 0.72 & 72.4 & 32.4 & 1.3 & 0.3 & A \\
\hline $\mathrm{P} 2 \mathrm{AB}$ & 46.6 & 2.6 & $20-450$ & 11 & 0.90 & 0.85 & 13.8 & 4.6 & 2.9 & 3.9 & A \\
\hline $\mathrm{P} 2 \mathrm{AC}$ & 46.9 & 2.0 & $100-275$ & 5 & 0.83 & 0.70 & 13.8 & 8.0 & 2.8 & 0.7 & A \\
\hline $\mathrm{P} 2 \mathrm{~B}$ & 63.0 & 2.7 & $20-250$ & 5 & 0.56 & 0.67 & 8.7 & 5.0 & 0.0 & 4.3 & A \\
\hline P2EY & 47.8 & 0.5 & $100-300$ & 6 & 0.78 & 0.78 & 55.2 & 27.6 & 1.9 & 5.5 & B \\
\hline $\mathrm{P} 2 \mathrm{KX}$ & 42.3 & 0.3 & $100-300$ & 6 & 0.54 & 0.71 & 53.1 & 26.6 & 0.2 & 2.8 & A \\
\hline P2NA & 52.0 & 1.8 & $20-250$ & 5 & 0.80 & 0.62 & 14.3 & 8.2 & 0.8 & 3.9 & A \\
\hline P2NB & 55.7 & 2.0 & $20-250$ & 5 & 0.41 & 0.64 & 7.3 & 4.2 & 1.0 & 0.0 & A \\
\hline $\mathrm{P} 2 \mathrm{O}$ & 40.3 & 1.4 & $100-450$ & 9 & 0.88 & 0.72 & 18.2 & 6.9 & 0.6 & 3.2 & B \\
\hline P2RL & 46.1 & 3.9 & $20-250$ & 5 & 0.31 & 0.63 & 2.3 & 1.3 & 0.1 & 8.3 & B \\
\hline $\mathrm{P} 2 \mathrm{~S}$ & 60.3 & 1.8 & $225-325$ & 5 & 0.59 & 0.68 & 13.9 & 8.0 & 3.4 & 0.8 & B \\
\hline \multicolumn{12}{|c|}{ Vesuvius 1944 A.D. eruption } \\
\hline VM1DY & 54.7 & 5.3 & $20-650$ & 14 & 1.0 & 0.8 & 8.2 & 2.4 & 4.9 & 0.4 & A \\
\hline VM1G & 39.3 & 1.83 & $200-450$ & 9 & 0.67 & 0.83 & 12.0 & 4.5 & 3.6 & 4.5 & A \\
\hline VM1I & 33.5 & 3.3 & $20-250$ & 7 & 0.31 & 0.78 & 2.5 & 1.1 & 0.1 & 5.8 & A \\
\hline VM1KX & 37.7 & 1.0 & $20-300$ & 5 & 0.45 & 0.67 & 11.1 & 6.4 & 1.0 & 2.3 & A \\
\hline VM1MX & 29.5 & 0.8 & $20-450$ & 11 & 0.87 & 0.86 & 26.4 & 8.8 & 4.3 & 5.6 & $\mathrm{~B}$ \\
\hline VM1MY & 33.2 & 0.2 & $100-300$ & 6 & 0.85 & 0.62 & 107.5 & 53.8 & 3.4 & 2.8 & A \\
\hline VM1NX & 32.5 & 1.1 & $20-550$ & 13 & 0.96 & 0.87 & 23.9 & 7.2 & 1.0 & 0.9 & A \\
\hline VM1Q & 27.9 & 2.4 & $20-250$ & 5 & 0.7 & 0.63 & 5.1 & 2.9 & 2.0 & 2.5 & A \\
\hline VM1RY & 62.8 & 3.2 & $20-450$ & 11 & 1.0 & 0.76 & 14.8 & 4.9 & 4.9 & 1.9 & A \\
\hline VM1S & 36.9 & 0.9 & $20-450$ & 8 & 0.9 & 0.75 & 29.3 & 12 & 2.8 & 2.9 & B \\
\hline VM2BY & 58.3 & 2.7 & $20-250$ & 5 & 0.39 & 0.68 & 5.8 & 3.4 & 2.9 & 1.2 & B \\
\hline VM2DY & 30.8 & 1.8 & $200-475$ & 7 & 0.64 & 0.82 & 9.3 & 4.2 & 1.9 & 10.8 & B \\
\hline VM2JX & 34.2 & 1.1 & $100-650$ & 14 & 0.96 & 0.85 & 25.4 & 7.3 & 3.4 & 3.0 & B \\
\hline VM2N & 58.1 & 3.4 & $20-275$ & 6 & 0.48 & 0.76 & 6.1 & 3.1 & 2.5 & 6.6 & B \\
\hline VM2OY & 77.2 & 5.5 & $20-300$ & 7 & 0.39 & 0.80 & 4.4 & 2.0 & 4.8 & 5.3 & B \\
\hline VM2S & 51.2 & 3.0 & $100-275$ & 7 & 0.53 & 0.81 & 7.4 & 3.3 & 6.9 & 8.3 & B \\
\hline VM2UX & 51.2 & 3.4 & $20-325$ & 8 & 0.70 & 0.82 & 8.6 & 3.5 & 5.9 & 10.3 & B \\
\hline VM2UY & 46.9 & 1.9 & $20-500$ & 11 & 0.75 & 0.88 & 16.0 & 5.3 & 5.7 & 8.1 & B \\
\hline
\end{tabular}

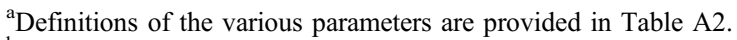

${ }^{\mathrm{b}} \Delta T$ is the temperature range used to make the paleointensity estimate.

in error. We find a calibration factor of $1900 \mu \mathrm{T}$ rather than $3000 \mu \mathrm{T}$ to yield a better mean result.

[87] Frequency histograms of the Preisach, Thellier, and REM normalized paleointensity estimates are shown in Figure 14. It is seen that the Preisach and REM methods have skewed distributions, whereas the Thellier method is more symmetrical. The application of the proposed MDF selection criteria from section 5.1.2, i.e., reject data with MDF values $>50 \mathrm{mT}$, removes several very high Preisach paleointensity estimates (Figure 14).

\section{Conclusions}

[88] This paper has tested the Preisach paleointensity method as proposed by Muxworthy and Heslop [2011], using a suite of synthetic samples and modern lavas and pyroclastic lithic clasts. For the results from the synthetic samples, the Preisach paleointensity estimates compare very favorably with the expected field and the results from Thellier-type results for well-behaved samples, i.e., more SD-like samples. For the MD synthetic sample, neither the Preisach nor the Thellier method returned accurate paleointensities. There were several suites of natural samples for which the Preisach method returned reliable paleointensity estimates. The Thellier method also returned accurate intensity estimates for some of these samples, but for cases where the Thellier-type estimates failed, e.g., the Mount St. Helens and Krafla samples, the Preisach method still produced estimates, although lower than the expected values. This may be due to 
Table A2. Summarizing the ThellierTool 4.1 Default Criteria ${ }^{\mathrm{a}}$

\begin{tabular}{|c|c|c|}
\hline Criteria Description & Class A & Class B \\
\hline \multicolumn{3}{|c|}{ Linear Fit Criteria } \\
\hline Number of points $(N)$ used to determine the paleointensity & $\geq 5$ & $\geq 5$ \\
\hline Normalized standard deviation of slope $(\beta)$ & $\leq 0.1$ & $\leq 0.15$ \\
\hline Fraction of NRM $(f)$ & $\geq 0.3$ & $\geq 0.3$ \\
\hline Quality factor $(q)$ & $\geq 1$ & $\geq 0$ \\
\hline \multicolumn{3}{|c|}{ Directional Criteria } \\
\hline Maximum angular deviation (MAD) of the anchored fit & $\leq 6^{\circ}$ & $\leq 15^{\circ}$ \\
\hline $\begin{array}{l}\text { Angular difference between the anchored and nonanchored } \\
\text { solution }(\alpha)\end{array}$ & $\leq 15^{\circ}$ & $\leq 15^{\circ}$ \\
\hline \multicolumn{3}{|c|}{ Alteration Criteria } \\
\hline $\begin{array}{l}\text { Maximum difference produced by a pTRM check, normalized } \\
\text { by the TRM }(\delta(\mathrm{CK}))\end{array}$ & $\leq 5 \%$ & $\leq 7 \%$ \\
\hline Cumulative difference produced by pTRM checks $\left(\delta_{p a l}\right)$ & $\leq 5 \%$ & $\leq 10 \%$ \\
\hline \multicolumn{3}{|c|}{ Repeated Demagnetization Steps } \\
\hline $\begin{array}{l}\text { Extent of pTRM tail after correction for angular dependence } \\
\text { pTRM }\left(\delta\left(t^{*}\right)\right)\end{array}$ & $\leq 3 \%$ & $\leq 5 \%$ \\
\hline $\begin{array}{l}\text { Maximum difference produced by a pTRM tail check, } \\
\text { normalized by the NRM }(\delta(\text { TR }))\end{array}$ & $\leq 10 \%$ & $\leq 20 \%$ \\
\hline
\end{tabular}

${ }^{\mathrm{a}}$ These parameters are described in more detail by Leonhardt et al. [2004, and references therein]. Common abbreviations for the symbols are in parentheses.

the presence of MD material, which is shown for the synthetic samples to underestimate the paleointensity. More work on the response of MD particles is required.

[89] In the theoretical development of the Preisach paleointensity method, Muxworthy and Heslop [2011] employed empirical relationships, which implies that natural samples should follow some form of average behavior. Compared to the nonheating calibrated relative paleointensity REM method, the Preisach paleointensity method is demonstrated to produce more accurate paleointensity estimates, lending support to the assumptions made in the underlying theory of the approach.

[90] We do not envisage the Preisach paleointensity method replacing Thellier-type protocols. We see it as complementary method, being used when samples are highly susceptible to chemical alteration on heating, i.e., samples such as chondrules, where the REM method is currently used to make paleofield estimates of the early Solar Nebular, or for samples that are too precious or rare to have a destructive Thellier-type method applied. If extensive measurements are to be made on meteoritic materials, than the empirically derived Barbier relationship should be verified for such material.

[91] There are potentially areas for improvement of the protocol, including: (1) directly determining the thermal fluctuation field for each individual sample rather than relying on the empirically derived relationship (the Barbier relationship), (2) testing the robustness of the Preisach distribution by comparing its predictions for a sample with further isothermal measurements (the method already does this for AF demagnetization data), (3) measuring thermomagnetic curves for each sample to determine the behavior of the saturation magnetization with temperature as a direct input into the protocol; however, such a procedure may lead to chemical alteration, (4) repeat measurement of the SIRM normalization parameter (in this study, the SIRM was only checked for consistency), and (5) the application of rejection criteria, such as the MDF rejection criteria proposed in section 5.1.2.

\section{Appendix A}

[92] Summary of the Thellier results obtained specifically for this study, i.e., the samples from the 1943 A.D. Paricutin eruption and the 1944 A.D. Vesuvius eruption (Table A1). Thellier data selection criteria used in this study were taken from the default criteria in the ThellierTool 4.1 software [Leonhardt et al., 2004]. All data summarized in Table A1 passed at least B default criteria (Table A2): (1) for Paricutin 29 out of 41 samples passed this criterion and (2) for Vesuvius 18 out of 27 passed this criterion. The paleointensity estimates were automatically determined by maximizing the weighting parameter $w$ [Prévot et al., 1985].

[93] Acknowledgments. This work was funded by NERC grant NE/D000351/1, the Royal Society, and the DFG. We would like to thank Harald Böhnel and Conall MacNiocaill for help with fieldwork in Mexico, and similarly John Maclennan, Margaret Hartley, and Karin Strohecker for assistance in Iceland. We thank Roman Leonhardt for providing the synthetic glass samples used in this study. Some measurements were made at the Institute for Rock Magnetism, University of Minnesota, which is funded by the National Science Foundation, W. M. Keck Foundation and the University of Minnesota.

\section{References}

Acton, G., Q. Z. Yin, K. L. Verosub, L. Jovane, A. Roth, B. Jacobsen, and D. S. Ebel (2007), Micromagnetic coercivity distributions and interactions in chondrules with implications for paleointensities of the early solar system, J. Geophys. Res., 112, B03S90, doi:10.1029/2006JB004655.

Banks, N. G., and R. P. Hoblitt (Eds.) (1981), Summary of temperature studies of 1980 deposits, pp. 295-313, U.S. Geol. Surv., Washington, D. C.

Barbier, J. C. (1954), Le traînage magnétique de fluctuation, Ann. Phys. (Paris), 9, 84-140.

Biggin, A. J., H. N. Böhnel, and F. R. Zuniga (2003), How many paleointensity determinations are required from a single lava flow to constitute a reliable average?, Geophys. Res. Lett., 30(11), 1575, doi:10.1029/ 2003GL017146. 
Bol'shakov, A. S., and V. V. Shcherbakova (1979), A thermomagnetic criterion for determining the domain structure of ferrimagnetics, Izvest. Earth Phys., 15, 111-117.

Borcia, I. D., L. Spinu, and A. Stancu (2002), A Preisach-Néel model with thermally variable variance, IEEE Trans. Magn., 38(5), 2415-2417, doi:10.1109/TMAG.2002.803611.

Borradaile, G. (2003), Statistics of Earth Science Data: Their Distribution in Time, Space and Orientation, 351 pp., Springer, Heidelberg, Germany. Carvallo, C., A. P. Roberts, R. Leonhardt, C. Laj, C. Kissel, M. Perrin, and P. Camps (2006), Increasing the efficiency of paleointensity analyses by selection of samples using first-order reversal curve diagrams, J. Geophys. Res., 111, B12103, doi:10.1029/2005JB004126.

Coe, R. S. (1967), The determination of paleointensities of the Earth's magnetic field with emphasis on mechanisms which could cause non-ideal behavior in Thellier's method, J. Geomagn. Geoelectr., 19, 157-179.

Day, R., M. D. Fuller, and V. A. Schmidt (1977), Hysteresis properties of titanomagnetites: Grain-size and compositional dependence, Phys. Earth Planet. Inter., 13, 260-267, doi:10.1016/0031-9201(77)90108-X.

Dekkers, M. J., and H. N. Böhnel (2006), Reliable absolute palaeointensities independent of magnetic domain state, Earth Planet. Sci. Lett., 248(1-2), 508-517.

Dodson, M. H., and E. McClelland-Brown (1980), Magnetic blocking temperatures of single-domain grains during slow cooling, J. Geophys. Res., 85(B5), 2625-2637, doi:10.1029/JB085iB05p02625.

Fabian, K. (2006), Approach to saturation analysis of hysteresis measurements in rock magnetism and evidence for stress dominated magnetic anisotropy in young mid-ocean ridge basalt, Phys. Earth Planet. Inter., 154(3-4), 299-307, doi:10.1016/j.pepi.2005.06.016.

Ferk, A., F. W. v. Aulock, R. Leonhardt, K.-U. Hess, and D. B. Dingwell (2010), A cooling rate bias in paleointensity determination from volcanic glass: An experimental demonstration, J. Geophys. Res., 115, B08102, doi: $10.1029 / 2009 J B 006964$.

Finlay, C. C. (2008), Historical variation of the geomagnetic axial dipole, Phys. Earth Planet. Inter., 170(1-2), 1-14, doi:10.1016/j.pepi.2008.06.029.

Gattacceca, J., and P. Rochette (2004), Toward a robust normalized magnetic paleointensity method applied to meteorites, Earth Planet. Sci. Lett., 227(3-4), 377-393, doi:10.1016/j.eps1.2004.09.013.

Gubbins, D., A. L. Jones, and C. C. Finlay (2006), Fall in Earth's magnetic field is erratic, Science, 312(5775), 900-902, doi:10.1126/science. 1124855 .

Haggerty, S. E. (1991), Oxide textures-A mini-atlas, in Oxide Minerals: Petrologic and Magnetic Significance, Rev. Mineral., vol. 25, edited by D. H. Lindsley, pp. 129-137, Mineral. Soc. of Am., Washington, D. C.

Halgedahl, S. L., R. Day, and M. Fuller (1980), The effect of cooling rate on the intensity of weak-field TRM in single-domain magnetite, J. Geophys. Res., 85(B7), 3690-3698, doi:10.1029/JB085iB07p03690.

Hjartardóttir, Á., P. Einarsson, and H. Sigurdsson (2009), The fissure swarm of the Askja volcanic system along the divergent plate boundary of N Iceland, Bull. Volcanol., 71(9), 961-975, doi:10.1007/s00445-0090282-X.

Jackson, M. J., H.-U. Worm, and S. K. Banerjee (1990), Fourier analysis of digital hysteresis data: Rock magnetic applications, Phys. Earth Planet. Inter., 65, 78-87, doi:10.1016/0031-9201(90)90077-B.

Jackson, A., A. R. T. Jonkers, and M. R. Walker (2000), Four centuries of geomagnetic secular variation from historical records, Philos. Trans. $R$. Soc. London, Ser. A, 358, 957-990, doi:10.1098/rsta.2000.0569.

Kilburn, C., and W. McGuire (2001), Italian Volcanoes, 166 pp., Terra, Harpenden, U. K.

Kletetschka, G., P. J. Wasilewski, and P. T. Taylor (2000), Unique thermoremanent magnetization of multidomain sized hematite: Implications for magnetic anomalies, Earth Planet. Sci. Lett., 176(3-4), 469-479, doi:10.1016/S0012-821X(00)00016-9.

Kneller, E. (1969), Fine particle theory, in Magnetism and Metallurgy, edited by A. Berkowitz and E. Kneller, pp. 366-472, Academic, San Diego, Calif.

Krása, D., and J. Matzka (2007), Inversion of titanomaghemite in oceanic basalt during heating, Phys. Earth Planet. Inter., 160(2), 169-179, doi:10.1016/j.pepi.2006.11.004.

Leonhardt, R., J. Matzka, and E. A. Menor (2003), Absolute paleointensities and paleodirections of Miocene and Pliocene lavas from Fernando de Noronha, Brazil, Phys. Earth Planet. Inter., 139(3-4), 285-303, doi:10.1016/ j.pepi.2003.09.008

Leonhardt, R., C. Heunemann, and D. Krása (2004), Analyzing absolute paleointensity determinations: Acceptance criteria and the software ThellierTool4.0, Geochem. Geophys. Geosyst., 5, Q12016, doi:10.1029/ $2004 \mathrm{GC} 000807$.

McClelland-Brown, E. (1984), Experiments on TRM intensity dependence on cooling rate, Geophys. Res. Lett., 11(3), 205-208, doi:10.1029/ GL011i003p00205.
Michalk, D., A. R. Muxworthy, H. Böhnel, J. MacLennan, and N. R. Nowaczyk (2008), Evaluation of the multispecimen parallel differential pTRM method: A test on historical lavas from Iceland and Mexico, Geophys. J. Int., 173(2), 409-420, doi:10.1111/j.1365-246X.2008.03740.x.

Muxworthy, A. R., and D. J. Dunlop (2002), First-order reversal curve (FORC) diagrams for pseudo-single-domain magnetites at high temperature, Earth Planet. Sci. Lett., 203(1), 369-382, doi:10.1016/S0012821X(02)00880-4.

Muxworthy, A. R., and D. Heslop (2011), A Preisach method to estimate absolute paleofield intensity under the constraint of using only isothermal measurements: 1. Theoretical framework, J. Geophys. Res., 116, B04102, doi:10.1029/2010JB007843.

Muxworthy, A. R., and A. P. Roberts (2007), First-order reversal curve (FORC) diagrams, in Encyclopedia of Geomagnetism and Paleomagnetism, edited by E. Herrero-Bervera and D. Gubbins, pp. 266-272, Springer, Dordrecht, Netherlands, doi:10.1007/978-1-4020-4423-6 99.

Muxworthy, A. R., D. J. Dunlop, and Ö. Özdemir (2003), Low-temperature cycling of isothermal and anhysteretic remanence: Microcoercivity and magnetic memory, Earth Planet. Sci. Lett., 205(3-4), 173-184, doi:10.1016/S0012-821X(02)01039-7.

Muxworthy, A. R., D. Heslop, and W. Williams (2004), Influence of magnetostatic interactions on first-order-reversal-curve (FORC) diagrams: A micromagnetic approach, Geophys. J. Int., 158, 888-897, doi:10.1111/ j.1365-246X.2004.02358.x.

Muxworthy, A. R., J. G. King, and D. Heslop (2005), Assessing the ability of first-order-reversal-curve (FORC) diagrams to unravel complex magnetic signals, J. Geophys. Res., 110, B01105, doi:10.1029/2004JB003195.

Muxworthy, A. R., D. Heslop, and D. M. Michalk (2009), Thermal fluctuation fields in basalts, Earth Planets Space, 61(1), 111-117.

Nagata, T., Y. Arai, and K. Momose (1963), Secular variation of the geomagnetic total force during the last 5000 years, J. Geophys. Res., 68 , 5277-5281.

Newell, A. J. (2005), A high-precision model of first-order reversal curve (FORC) functions for single-domain ferromagnets with uniaxial anisotropy, Geochem. Geophys. Geosyst., 6, Q05010, doi:10.1029/2004GC000877.

Paterson, G. A., D. Heslop, and A. R. Muxworthy (2010a), Deriving confidence in paleointensity estimates, Geochem. Geophys. Geosyst., 11 Q07Z18, doi:10.1029/2010GC003071.

Paterson, G. A., A. R. Muxworthy, A. P. Roberts, and C. Mac Niocaill $(2010 \mathrm{~b})$, Assessment of the usefulness of lithic clasts from pyroclastic deposits for paleointensity determination, J. Geophys. Res., 115, B03104, doi:10.1029/2009JB006475.

Paterson, G. A., A. P. Roberts, A. R. Muxworthy, C. Mac Niocaill, L. Gurioli, J. G. Viramont, and C. Navarro (2010c), Palaeomagnetic determination of emplacement temeperatures of pyroclastic deposits: An under-utilized tool, Bull. Volcanol., 72(3), 309-330, doi:10.1007/ s00445-009-0324-4.

Petersen, N., and H. Vali (1987), Observation of shrinkage cracks in ocean floor titanomagnetite, Phys. Earth Planet. Inter., 46, 197-205, doi:10.1016/00319201(87)90182-8

Prévot, M., E. A. Mankinen, R. S. Coe, and C. S. Grommé (1985), The Steens Mountain (Oregon) geomagnetic polarity transition: 2. Field intensity variations and discussion of reversal models, J. Geophys. Res., 90(B12), 10,417-10,448, doi:10.1029/JB090iB12p10417.

Roberts, A. P., C. R. Pike, and K. L. Verosub (2000), First-order reversal curve diagrams: A new tool for characterizing the magnetic properties of natural samples, J. Geophys. Res., 105(B12), 28,461-28,475, doi:10.1029/ 2000JB900326.

Sparks, R. S. J., M. C. Gardeweg, E. S. Calder, and S. J. Matthews (1997), Erosion by pyroclastic flows on Lascar Volcano, Chile, Bull. Volcanol., 58(7), 557-565, doi:10.1007/s004450050162.

Spinu, L., I. D. Borcia, A. Stancu, and C. J. O'Connor (2001), Time and temperature-dependent Preisach models, Physica B, 306(1-4), 166-171, doi:10.1016/S0921-4526(01)00998-X.

Thellier, E., and O. Thellier (1959), Sur l'intensité du champ magnétique terrestre dans le passé historique et géologique, Ann. Geophys., 15, 285-376.

Urrutia-Fucugauchi, J., L. M. Alva-Valdivia, A. Goguitchaichvili, M. L. Rivas, and J. Morales (2004), Palaeomagnetic, rock-magnetic and microscopy studies of historic lava flows from the Paricutin volcano, Mexico: Implications for the deflection of palaeomagnetic directions, Geophys. J. Int., 156(3), 431-442, doi:10.1111/j.1365-246X.2004.02166.x.

Walton, D. (1984), Re-evaluation of Greek archaeomagnetic intensities, Nature, 310, 740-743, doi:10.1038/310740a0.

Wang, D., R. Van der Voo, and D. R. Peacor (2006), Low-temperature alteration and magnetic changes of variably altered pillow basalts, Geophys. J. Int., 164(1), 25-35, doi:10.1111/j.1365-246X.2005.02819.x.

Wohlfarth, E. P. (1984), The coefficient of magnetic viscosity, J. Phys. F Met. Phys., 14, L155-L159, doi:10.1088/0305-4608/14/8/005. 
Yu, Y. J., L. Tauxe, and A. Genevey (2004), Toward an optimal geomagnetic field intensity determination technique, Geochem. Geophys. Geosyst., 5, Q02H07, doi:10.1029/2003GC000630.

Zijderveld, J. D. A. (1967), A. C. demagnetization of rocks: Analysis of results, in Methods in Palaeomagnetism, edited by D. W. Collinson, K. M. Creer, and S. K. Runcorn, pp. 254-286, Elsevier, Amsterdam.

D. Heslop, Research School of Earth Sciences, Australian National University, Canberra ACT 0200, Australia.
D. Michalk, Helmholz-Zentrum Potsdam, Deutsches GeoForschungsZentrum, Sektion 5.2, Telegrafenberg, D-14473 Potsdam, Germany.

A. R. Muxworthy, Department of Earth Science and Engineering, Imperial College London, South Kensington Campus, London, SW7 2AZ, UK. (adrian.muxworthy@imperial.ac.uk)

G. A. Paterson, School of Ocean and Earth Sciences, National Oceanography Centre, University of Southampton, Southampton, SO14 $3 \mathrm{ZH}, \mathrm{UK}$. 